\title{
Examining the effect of life course events on modality type and the moderating influence of life stage
}

\author{
Julia Janke ${ }^{1}$ (D) Calvin G. Thigpen ${ }^{2}$ (D) . Susan Handy ${ }^{3}$ (D) \\ Published online: 20 February 2020 \\ (C) The Author(s) 2020
}

\begin{abstract}
Previous research has demonstrated the relevance of life events to explain changes in travel behavior. Less clear is the moderating role played by life stages on the relationship between life events and travel behavior. Our goal in this study is to explore how the influence of life events on travel behavior differs by life stage. We use data from a travel survey of faculty, staff and students at a US university. We define four life stages: millennials living in shared apartments or alone, millennials living with partners, parents (of any generation) living with their children, and non-millennial adults living without children. Four modality types were defined: active travelers, car users, transit users, and multimodal travelers. We use a Manifest Markov Model to estimate probabilities of switching modality types between two waves of the survey. Life stage does not significantly moderate effects of life events on change in travel behavior but does affect modality type: the prevalence of active travel modality types, particularly the share of women who are active travelers, decreases throughout the life stages. Millennials living with their partners and parents living with their children relocate to another town more often than those in other life stages, a life event associated with a higher probability of switching to car use only. Our results identify "windows of opportunity", such as residential relocation, that planners can use to promote sustainable travel behavior.
\end{abstract}

Keywords Life course events $\cdot$ Travel behavior change $\cdot$ Multimodality $\cdot$ Manifest Markov model

Julia Janke

julia.janke@tuwien.ac.at

Calvin G. Thigpen

cthigpen@asu.edu

Susan Handy

slhandy@ucdavis.edu

1 Department of Spatial Planning, TU Wien, Karlsplatz 13, 1040 Vienna, Austria

2 School of Geographical Sciences and Urban Planning, Arizona State University, P.O. Box 875302, Tempe, AZ 85287-5302, USA

3 Institute of Transportation Studies, University of California, Davis, Davis, CA 95616, USA 


\section{Introduction}

In everyday life, travelers rarely change their behavior. Studies show that daily travel behavior is often habitual, characterized by routines (Müggenburg et al. 2015). However, in the presence of major changes in other life domains, individuals more deliberatively reflect on their travel behavior and their mode choices become more intentional (Müggenburg et al. 2015). Research in the domain of mobility biographies more explicitly links long-term decisions such as residential location choice to short-term decisions such as transport mode choice. Some researchers have argued that these life events open "windows of opportunities" during which policy interventions and programs may more effectively trigger change towards more sustainable travel behavior.

The impact of these life events might depend on the context of an individual's life stage. The different mental and physical capacities, financial constraints, and social responsibilities that individuals face at different stages of life might enhance or dampen the effect of life events on travel behavior. Recent research suggests that young persons of the millennial generation behave differently, a phenomenon partly explained by a delay in life stage. More specifically, several studies show generational differences between "millennials" and members of "generation X" with respect to car ownership, transit use, and residential location preferences (for California, US: Circella et al. 2017; Thigpen and Handy 2018; for the UK: Chatterjee et al. 2018; for Australia: Delbosc and Currie 2014a, b; Delbosc and Nakanishi 2017; Raimond and Milthorpe 2010; for Germany: Bohnet and Gertz 2010; Kuhnimhof et al. 2012; for France: Licaj et al. 2012; for Japan: Zhang et al. 2017). Though these may represent durable differences between generations, they also may be temporary and reflect delays in transitioning to other life stages (Delbosc and Currie 2013; McDonald 2015). For example, young couples today often decide to move in together or to build a family at later ages than previous generations, which also affects financial and mobility resources (Chatterjee et al. 2018). It remains unclear if households at different life stages or of different generations react similarly to life events with respect to changes in their travel behavior.

One aspect of travel behavior that is increasingly relevant, given the rise of shared mobility, and could be especially sensitive to life events is multimodality, defined as the use of multiple modes of travel for commute trips or other trips. Many travel behavior studies focus on the primary mode of transportation as an indicator. As ride-hailing and shared-mobility services extend the variety of modes available in the US, understanding multimodal travel is increasingly important. Multimodality may also serve as a transitional pattern of behavior away from exclusive car use. Previous studies, for example, have shown that car users who also use bicycle are more likely to switch to public transport use than strict car users (Kroesen 2014). Others have pointed out that strict car users tend to stick to their mode, but if they switch mode, they may be more likely to switch to multimodal travel (De Haas et al. 2018).

This paper investigates, first, the impact of life events on travel behavior change, and, second, whether the influence of life events on travel behavior change varies across life stages. We aim to contribute to the discussion about millennials' travel behavior by examining whether this generation reacts differently to life events depending on their life stage. We focus on changes in multimodal travel over time using panel data from a travel survey at the University of California, Davis (UC Davis) about modes of travel to campus by students, staff, and faculty. The findings show that life events provide explanatory power for changes in travel behavior, but that life stage does not moderate this relationship. Gender and generational differences between millennials and non-millennials, however, play a role in explaining modality type and 
are linked to life stage. Life events have different effects on the probability of transitioning from one modality type to another depending on the initial modality type. Our results highlight that most people do not change their modality types in response to life events, and that this is particularly true for drivers. They also point to potential synergies for integrative planning, for instance combining planning for housing and transportation to induce behavioral change.

\section{Literature review and conceptual approach}

To improve the sustainability of the current transportation system, it is important to understand how and why travel behavior changes. Recent attention has focused on the mobility biography and life-course approach to explain travel behavior change with numerous publications in journals, for example in the special issue of Zhang and Van Acker (2017), the literature review of Müggenburg et al. (2015) and books (e.g. Scheiner and Holz-Rau 2015; Zhang 2017). A lifecourse approach focuses on the relationship between life events, life stage, and travel behavior and links short- and long-term decisions. Key life events can be defined as "major event[s] in a personal life that will trigger a process of reconsidering current behavior" (Van der Waerden et al. 2003, p. 2). Lanzendorf (2003) establishes the concept of mobility biographies proposing a framework that causally links events in the lifestyle (e.g. family foundation) and accessibility domains (e.g. workplace, residence) to the mobility domain (e.g. car ownership). The theoretical background of this approach suggests that daily travel is driven by habits and individuals tend to not scrutinize routines (Holz-Rau and Scheiner 2015). Key life events may interrupt these habits and unleash a deliberation process during which people reconsider their mode choices and travel behavior in general (Chatterjee et al. 2013). This deliberation process may be moderated by personal history (e.g. crashes, previous travel experiences), intrinsic motivations (e.g. attitudes) and external conditions (e.g. supportive employer for bicycling) (Chatterjee et al. 2013; Flamm and Kaufmann 2006; Lee et al. 2015; Smart and Klein 2017; Thigpen 2019).

\section{Life events trigger change in travel behavior}

Several studies have found evidence for the influence of life events on travel behavior change (Clark et al. 2016; Beige and Axhausen 2017; Dargay and Hanly 2004; Oakil et al. 2016; Scheiner and Holz-Rau 2015; Verhoeven et al. 2005). For the UK, Clark et al. (2016) using a longitudinal dataset found that a higher share of commuters who experienced changes in the workplace and residential location switched mode compared to commuters who did not experience life events. These results still hold when the availability of public transport and commute distance are taken into account and point to a separate effect of life events on commute behavior. Besides changes in residential location and employment, the acquisition of a driver's license and children moving out of the household have been shown to affect car ownership and individual travel behavior (Beige and Axhausen 2017; Dargay and Hanly 2004; Oakil et al. 2014). An increase in household size such as cohabitation or a childbirth positively influences car ownership while divorce has a negative effect (Oakil et al. 2014). A child leaving home has no significant effect on car ownership, but retirement is connected with a reduction in the number of cars in the household (Oakil et al. 2014). For Dutch travelers, Oakil et al. (2016) showed that households who experience childbirth are more likely to switch from bicycle commuting to other modes, though cohabitation increases the probability of switching to bicycle commuting. 


\section{Life events and change in multimodal travel behavior}

Only a few studies have examined the impact of life events on the use of multiple modes of travel—multimodal travel—in a quantitative way. Multimodality generally refers to the travel pattern of a person who uses several modes over a defined period of time (e.g. day, week or a longer period) (Scheiner et al. 2016).

Scheiner et al. (2016) found that certain life course events are significantly associated with changes in multimodal behavior: children moving out increased parent's multimodality; individuals who entered the labor market decreased their multimodal travel while the opposite is true for individuals who exited the labor market; an increase in car availability led to a decrease in multimodality and vice versa. In a latent class analysis, Kroesen (2014) found that subsequently residential relocation, strict bicyclists were more likely to become strict car users and strict car users to become public transport users. Change in employment increased the share of public transport users. In another Dutch study, De Haas et al. (2018) found that changes in employment increased the probability of becoming a strict car user except for individuals who also used public transport. Residential relocation affected unimodal users less but led bicycle and car users to shift to strict car use and individuals who walked and used a bicycle to shift to lower mobility classes or public transport. Their results demonstrated that a child's birth affects its parents' multimodality patterns, increasing the probability of becoming a strict car user or a multimodal user of car and walking. In their model, changing or starting an educational program increased the likelihood of becoming a public transport user. All of these studies have established evidence that life events affect multimodal travel though in some cases they observed different directions of change.

\section{Life stage influences travel behavior}

Travel behavior also varies between life stages. An individual life course can be divided into sequences - life stages - that mark periods with different living circumstances influencing behavior, attitudes and preferences (Holz-Rau and Scheiner 2015; Van Acker 2017). There is no one standard classification of life stages (Frey et al. 2017), though commonly distinguished stages include childhood, young adulthood, living with a partner, early career, marriage, parenthood, and retirement (Gilly and Enis 1982). Recent trends towards more complex, non-linear life courses (e.g. divorce and re-marriage) makes it more complicated to approximate a life stage with age only. Travel behavior research usually considers a number of sociodemographic factors that can be related to specific life stages.

Several studies show that travel behavior differs between life stages (Beige and Axhausen 2008; Clark et al. 2016; Chatterjee et al. 2012, 2013; Sun et al. 2009). Beige and Axhausen assessed travel behavior over a 20-year period with retrospective questions and revealed that car ownership increases after the age of 18 and is the highest for the age group between 25 and 50 years while the opposite is true for national and regional seasonal public transport tickets (Beige and Axhausen 2008). With the same data, the authors observed that the main mode of transport to the workplace is relatively stable throughout aging while bicycling tends to decrease in the late 40s and public transport use in the 60s (Beige and Axhausen 2017). The results of another study indicate that life stage better explained the number of trips made per day than did variation in the built environment (Sun et al. 2009). The number of trips did not increase linearly with age: parents with young children had the highest number of trips while single households (below as well as above 60 years old) the 
lowest (Sun et al. 2009). Clark et al. (2016) found that individuals in the age group between 16 and 29 are more likely to switch to car commute than other groups are. Chatterjee et al. (2012) point out that the nature of behavioral influence on bicycling changes over the life course. Young adults were prompted to start bicycling with the beginning of their studies or employment, older adults started bicycling because of health benefits (Chatterjee et al. 2013).

Recently, researchers have addressed the question of whether young persons behave differently in a more fundamental way. Several studies have reported changes in travel behavior for the millennial generation (for US: Circella et al. 2017; McDonald 2015; Thigpen and Handy 2018; for the UK: Chatterjee et al. 2018; for Australia: Delbosc and Currie 2014a, b; Delbosc and Nakanishi 2017; Raimond and Milthorpe 2010; for Germany: Bohnet and Gertz 2010; Kuhnimhof et al. 2012; for France: Licaj et al. 2012; for Japan: Zhang et al. 2017). These studies have observed changes in travel behavior that include postponed acquisition of driver's license, lower car ownership, less car driving and more use of public transport. But no consensus has emerged yet as to whether the observed differences can be attributed to lasting factors such as changes in lifestyle, preferences, and values or by temporal differences such as a delay in life stages (i.e. longer time passed in education, later parenthood). For example, young couples today often decide to move in together or to build a family at later ages than previous generations, which also affects financial and mobility resources (Chatterjee et al. 2018). For the UK, Chatterjee et al. (2018) found that young persons (17-29 years old) tend to drive more when they move into their 30s but still drive less than previous cohorts. Other studies have found life stage (child-rearing, part/ full-time employment) to be an important factor explaining differences in licensing (Delbosc and Currie 2013, 2014a, b). Comparing millennials to persons of the previous generation (Generation X) in California, Circella et al. (2017) found that millennials tend to use multiple modes and drive less than the previous generation. Although car ownership was lower for millennials especially for those living in urban cores, older millennials indicated the desire to purchase a car in the future, thereby supporting the hypothesis of a temporary change in behavior. Though millennials may prefer urban centers for living, they may be obliged to locate in suburban areas at later life stages due to high housing prices and then switch to car use (Delbosc and Nakanishi 2017).

Together, life stage affects ownership of mobility tools, transport mode choice particularly bicycling and the number of trips. Though some changes follow aging others show non-linear effects in relation to age and point to a separate effect of life stage that may not be well approximated by age only.

\section{The moderating role of life stage on the effect of life events for travel behavior change}

The relationships between life events, life stage and travel behavior are varied and complex. Some life events mark the transition from one life stage to another, indicating the beginning of a new life stage. For instance, a change in the number of household members may mark the starting of the life stage of parenthood or cohabitation with a partner. At the same time, life events may have different effects on travel behavior depending on the life stage. Research shows that travel needs and mode-related attitudes vary over the course of a person's life as they move through different life stages (Lanzendorf 2010; Sharmeen et al. 2014), thereby suggesting that the influence of life events on travel may be moderated by life stage. For instance, preferences for residential locations, which affect travel behavior, 
may change: a British study highlighted that young parents are more likely to move to better neighborhoods than others (Rabe and Taylor 2010).

Life stage may be linked to financial and organizational resources leading to differences in capacities to adapt. Cohabitation allows partners to pool resources and may increase car use (Scheiner and Holz-Rau 2013). The wish to purchase property often overlays with the life stage of parenthood or advanced professional career (Thierstein et al. 2016), but constrained housing markets often drive parents to locate in more car-dependent suburban areas to meet their demand for property and living space (Delbosc and Nakanishi 2017; Gehrke et al. 2019; Thierstein et al. 2016). In a Dutch study, young persons (aged 30 years or less) had a higher likelihood compared to older persons of giving up bicycle commute whereas no significant effects were found for persons older than 50 years (Oakil et al. 2016).

Over the life course, individuals may be less likely to change their travel behavior in the occurrence of life events because they are more likely to own a car and may be reluctant to abandon it. In fact, car ownership is less stable for young households (defined as head of household between 18 and 24 years old) than for older households (Dargay and Hanly 2004). In the same study, reducing car ownership to zero is also more prevalent for young households or households over 65 years compared to households in the middle age group (24 to 64 years old). In a Swiss study, retrospective data over a 20 -year period showed that stability in the ownership of mobility tools increases with age (Beige and Axhausen 2008). Increasing stability in mobility resources may explain why persons react differently to life events at distinct life stages. In contrast, Cheng et al. (2019) found for Chinese respondents that elderly persons are more affected by residential relocation than younger persons with respect to their travel frequency and duration. In addition, the frequency of life events may vary throughout the life course. Young persons may be used to adapting to new circumstances. In a Dutch study, young persons frequently changed their residence and workplace making a switch from bicycle to car commute more likely (Oakil et al. 2016).

In general, few studies have empirically investigated mode choice in this context.

\section{Model conceptualization}

Our study is embedded in the concept of mobility biographies as a framework for studying travel behavior change. Informed by the literature review, we identify two main research gaps.

Though several studies have established evidence that life events affect travel behavior change, it is unclear whether a person's life stage alters this effect. Studying the moderating effect of life stage may provide additional insights into the conditions under which travel behavior changes. These insights can inform transport policies that aim to incentivize more sustainable travel. Transport management programs, for example, that provide mobility-asa-service packages to recent movers may be more effective if targeted to persons who are more likely to change. Likewise, these packages themselves might be adapted to the preferences of different life stage groups. An analysis differentiated along life stages enables a more detailed exploration of behavioral differences observed for the millennial generation.

In addition, only a few studies have discussed multimodal travel behavior from a mobility biographies perspective. Multimodal travel more accurately describes actual travel patterns than does a simple analysis of mode split. For instance, about $25 \%$ of car users in the US make at least seven trips during a typical week by means of transport other than car according to the 2009 US National Household Travel Survey (Buehler and Hamre 2016). 


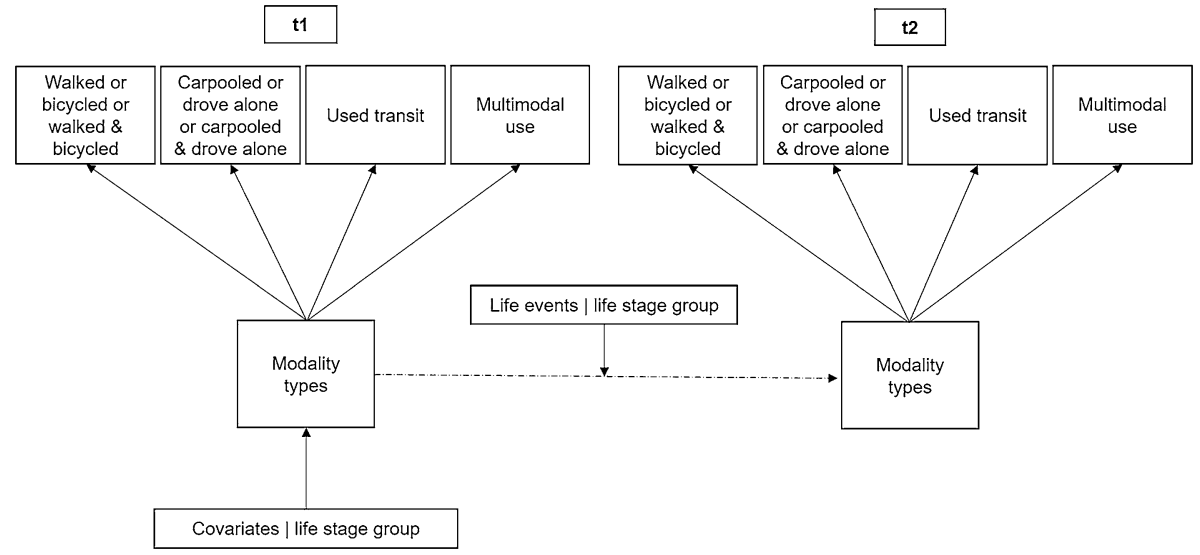

Fig. 1 Conceptual model [based on De Haas et al. (2018) and Kroesen (2014)]

Multimodal travel may also be relevant from a policy perspective. Studies have shown that strict car users are more likely to switch to multimodal than unimodal use (De Haas et al. 2018). Another study reported that young persons may be mode agnostic in choosing whatever mode is best suited best for the given circumstances (Delbosc and Nakanishi 2017). Young persons may be more likely to travel with multiple modes.

Our conceptual model provides the basis for addressing these gaps and is inspired by Kroesen (2014) and De Haas et al. (2018). With this approach, we attempt to answer two research questions: First, to what extent do life course events effect change in multimodal travel behavior? Second, to what extent do life course events affect multimodal travel behavior differently at distinct life stages?

In the university travel survey that we use, travel behavior is measured as the number of days a person traveled to campus with a specific mode out of five possible weekdays. We define modality types based on multimodal travel behavior as highlighted in Fig. 1. The dataset captures modality types at two points in time for each person. The model has two parts: one part determines the influence of covariates on modality type membership, the other the transition probability of switching to another modality type between time points. Socio-demographic factors and travel-related attitudes affect the modality type at the first point in time while life events and the previous modality type influence the probability of transitioning to another modality type. We use covariates in the membership model and life events in the transition model that depend on life stage groups to investigate the interaction between life stage groups and multimodal travel patterns as well as transition probabilities.

\section{Methods and data}

\section{Study area}

The setting for this study, which focuses on commuters to the UC Davis campus, offers a good opportunity to study multimodality. Most persons in our sample of commuters (79 percent) live in Davis, a small college town with 66,000 inhabitants. Davis is relatively densely populated for a US town of this size and has limited industrial land 
uses. A university-run bus system connects all residential neighborhoods in Davis to the campus, providing a good alternative to driving or bicycling. Davis has an extensive on-street and off-street bicycle network that far exceeds the bicycle infrastructure found in the typical US city (Buehler and Handy 2008). Due to the high number of bicycle commuters (compared to the US average), this sample may provide a good opportunity to understand the circumstances under which active travelers switch to strict car use and vice versa. A smaller share of the sample lives outside of Davis. Accessibility to transit for persons living outside of Davis varies depending on their residential location, and use of non-motorized modes is not feasible for most commuters given the long distances to campus.

\section{Sample description}

UC Davis has conducted an annual campus travel survey (CTS) since the 2006-07 school year (e.g. Wei 2018). Each fall, a UC Davis graduate student administers the CTS to a stratified random sample of students, staff, and faculty. The survey typically achieves a response rate of 10 to 21 percent of the invited sample. The survey asks respondents about commute travel, travel attitudes, and socio-demographic characteristics. In this study, we analyze longitudinal panel data from the most recent eight CTSs (2010-2017) (see Thigpen 2019 for more information about this panel). In the overall panel sample (3471 persons), $75 \%$ of the persons answered the survey twice and $25 \%$ three times or more. We chose to construct a two-wave dataset with two points of observation in time per person. For those who answered more than twice, we preferentially selected the pair with the least amount of difference (e.g. 1 year between paired observations) and the most recent pair. Sixty-eight percent of the persons answered 1 year after their first survey, $20 \%$ in a 2 -year interval and $12 \%$ in more than 2-year interval. To account for heterogeneity in the reporting period, we include a time variable as described below.

Since our sample is drawn from a university population, it differs from the average US population in terms of age, educational attainment, and the homogeneous trip destination. Respondents in our sample may have a higher variety of transport modes at their disposal than residents of other small-sized US towns, as the UC Davis campus is easily accessible by bus, bicycle, walking, and driving, though car parking is relatively costly. On the other hand, the variety of transport modes allows the study of multimodal travel more fully than is possible in other US cities of this size. In particular, the remarkable bicycle infrastructure and high level of bicycle commuting in Davis allows us to study switching from and to bicycle commuting.

With respect to our research question, differences between life stages may be less pronounced in a university population since students, staff, and faculty have relatively flexible work schedules and may be less time-constrained compared to non-university workers of the same age group. On the other hand, this study may be more likely to capture the causal effects of life events on change in travel behavior because of the relatively universal public transport and bicycling infrastructure within Davis. Although the university sample may diverge in the beforementioned aspects from the general population, it also provides advantages for the purposes of this study. 


\section{Definition of modality types}

We classify respondents into modality types to account for a set of travel modes that share similarities or complement each other (Kroesen 2014). It is assumed that modality styles reflect latent modal preferences that are based on travel-related attitudes, lifestyle choices, and/or emotional constraints (Vij et al. 2013). In the survey, participants were asked to indicate their primary mode of travel to campus on each day of the preceding week. Participants could choose from among five transport modes for each weekday: walking, biking, driving alone in a car, carpooling, and using transit. We defined four modality types based on the responses to this question. The first modality type encompasses active travelers who either only bicycle or only walk or bicycle and walk to campus over the week (at most 5 days). The second modality type includes car users: persons who only drive alone to campus, persons who only carpool, or persons who only do both. Persons who only use transit to travel to UC Davis are placed in the third modality type, transit users. The fourth type comprises multimodal users who are not in one of the previous types. They mostly bicycle to campus (on average two out of 5 days), also use transit (on average 1.3 days), drive alone in a car (about 1 day on average), but walk and carpool less often to campus. It is important to note that in this study, multimodal travel behavior relates to the different primary modes chosen over a week for traveling to campus and not different modes used on one trip.

\section{Definition of life course events}

Five life events are included in the analysis: residential relocation, changes in household size, changes in the role at UC Davis, and changes in the option to drive alone and to carpool. Residential relocation, the first type of life event, includes changes in residence within Davis and relocation from another town to Davis or vice versa. Residential moves are typically included in mobility biography analyses since spatial activity patterns may change and individuals must deliberate their mode choice in planning their travel (Chatterjee et al. 2013; Holz-Rau and Scheiner 2015). Changes in the number of persons living in the household are also considered life events. Several studies have found evidence that changes in travel behavior are significantly related to the moving out of children, cohabitation with partners, or moving out of partners (Müggenburg et al. 2015). Life events may mark a transition from one life stage to another as an increase in household members may indicate the beginning of parenthood. Since we cannot distinguish between childbirth or the moving in or out of a partner, child or another family member, we use the more general life event (i.e. change in household size). Changes in the role at UC Davis are considered to be a life event because they may be associated with changes in income, professional responsibility or advances in professional career, which have been found to be influential for travel behavior change (Dargay 2001; Oakil et al. 2014). Changes in role at UC Davis include any changes between the following groups: undergraduate student, graduate student, faculty, staff, visiting scholar, post doc, recent graduate, and retiree. Changes in the availability of a car to ride as a passenger or to drive alone in a car alter the mobility resources available for travel and are defined as the fifth type of life event. In the mobility biography literature, car ownership is considered to be part of the mobility domain (based on Lanzendorf's (2003) concept). Several studies have analyzed the effect of life events on car ownership (Oakil et al. 2014; Zhang 2017) whereas we consider changes in the possibility of driving in a 
car alone or carpooling as a life event. Endogeneity problems may arise since choosing the car-orientated modality type depends on having the option to carpool or to drive alone, while the latter might also be the outcome of a desire for the former. Still, we include the acquisition of the ability to drive or carpool as a life event because we are interested in how changes in these mobility tools affect the probability of choosing other modality types (active modes, transit, or multimodal travel.

Other life events are also of interest (e.g. children moving out) but could not be included in this analysis because the information was not collected, was not precise enough, or did not make sense in the context of this sample (e.g. employment changes). We consider the direction of change for all life events (except role at UC Davis) since the literature has shown that direction of change matters [e.g. for car ownership (Dargay 2001), for household size (Oakil et al. 2014)].

\section{Definition of life stages and hypotheses}

We define four life stage groups: millennials (currently aged 18-36) living alone or with roommates, millennials living with their partners, parents (of any generation) living with their children, and non-millennial adults (above 36 years old) living without their children. Our analysis is driven by several hypotheses about the effect of life stage groups.

The first two life stage groups include millennials at different life stages to contribute to the discussion on whether millennials behave differently due to delayed life stages. Several studies have reported changes in travel behavior for the millennial generation (as noted in the Literature Review). We distinguish millennials who live alone, in dorms, or in shared apartments (first life stage group) from millennials living with their partners (second life stage group). The first life stage group includes mostly undergraduate and graduate students who may have greater flexibility in their schedules and fewer professional responsibilities that affect their daily travel. Some researchers have found that young persons were somewhat "mode agnostic" individuals who chose the mode best suited in the given circumstances (Delbosc and Nakanishi 2017) and more likely to change their travel behavior than older individuals (Kroesen 2014). Our hypothesis related to the first life stage group is as follows:

Millennials living alone or with roommates use more modes in their commutes and are more likely to change their mode in the presence of life events because they are less constrained by the travel needs of others or by professional responsibilities.

The second life stage group comprises millennials who live with their partners. On one hand, members of this group might have more constraints on residential location, which must meet the needs of two people, and on travel, which must be coordinated with the partner, than millennials living on their own (Oostendorp 2014). On the other, they are likely to share mobility resources and trips with their partners (Scheiner and Holz-Rau 2013). This categorization may allow us to investigate whether cohabitation makes a difference how millennials react to life events. Our hypotheses related to the second life stage group is as follows:

Millennials who live with their partners are more likely to use a car, particularly to carpool, because they may share mobility resources. They may use different modes including the car over the week. They are more responsive to life events than millennials living alone or with roommates or parents living with their children because they are generally less constrained and have greater financial and mobility resources. 
The third group is distinguished from other life stages by parenthood. Previous studies have shown that parenthood is an important life stage in an individual's life course that affects travel behavior (e.g. De Haas et al. 2018; Lanzendorf 2010). Parents may be more car-dependent than other life stage groups since they may transport their children to various activities (Lanzendorf 2010). They face major time and financial constraints that may alter their travel behavior compared to persons of the same age group without children. Our hypotheses related to the third life stage group include:

Parents living with their children are less likely to change their travel behavior following a life event because their travel also depends on the travel needs of other household members.

Finally, the fourth life stage group encompasses non-millennial adults living without children. Persons in this group are older than 36 years and probably more advanced in their professional careers with higher incomes. They have more financial resources to acquire new mobility tools but may be less flexible switching commute modes during the week due to their professional and private responsibilities. Over the life course, persons tend to stay loyal to car driving and are less likely to give away their car (Beige and Axhausen 2008; Dargay 2001; Fatmi and Habib 2016). This group also includes some emeriti faculty who tend to be less constrained by their working situation. Hypotheses related to the fourth life stage group are:

Non-millennial adults are less time-constrained and have greater financial resources, for instance to invest in a new car or bicycle, and are more likely to switch modes in the presence of life events.

Persons in other life stages such as retired persons or parents with children at different ages would have been interesting to explore but we are not able to distinguish them in the present dataset. But the life stages defined in this study allow us to investigate whether young persons differ significantly from parents and older adults in their responses to life events. This analysis may contribute to recent discussions about decline or stagnation in car ownership and use. In addition, we compare two millennial groups at different life stages, the results of which may add to discussions about generational differences or delay in life stage.

\section{Other covariates}

Previous studies have highlighted factors that are associated with mode choice: sociodemographic characteristics, availability of mobility tools, built environment indicators, attitudinal and trip related factors (e.g. Clark et al. 2016; De Haas et al. 2018). Since the survey did not consistently assess income, we include educational attainment as an indicator for socioeconomic status. Other socio-demographic characteristics are age, gender, household size, and perceived availability of the options to drive and to carpool. The availability of a car may provide a better indicator compared to the number of cars in a household because it reflects the allocation of cars within the household (Scheiner and HolzRau 2013). Numerous studies include mobility tools in transport mode choice models though some discuss potential endogeneity with respect to related mode choices (Dargay and Hanly 2004). We decided to include options to drive alone and to carpool because we are interested in the effect of these mobility tools on modality types other than the carorientated modality type. Since travel-related attitudes have been shown in prior studies 
to significantly explain mode choice (Bamberg 2006; Busch-Geertsema and Lanzendorf 2017; Gärling et al. 1998; Molin et al. 2014), we include attitudinal indicators as well. Participants responded to attitudinal statements related to the value of travel time, liking of biking, liking of driving, and the need for a car on a five-point Likert scale, from "strongly disagree" (1) to "Strongly agree" (5).

All commute trips have the same destination, the university campus, with a few exceptions of off-site locations. We include two self-reported transit accessibility variables: access to bus and access to train. While $75 \%$ of the sample population has access to bus only, seven percent have access to train services near their residence (cf. Table 1). We did not include any other built environment variables since Davis is relatively homogeneous with respect to its population density and bicycle infrastructure. All residential areas are well served by the university-run public transit system. We account for the different built environment that persons who live outside of Davis experience by including a residential location variable. Also, distance from residence to campus is not included since Davis is a small town with approximately a three-mile radius from the center to the city limits. The homogeneous built environment may increase the likelihood that we captured the causal effects of life events, because changes in travel behavior may be less likely to be linked to changes in unobserved variables, such as mobility culture or accessibility. The residential location variable (living in Davis, living outside of Davis) captures differences in the environment between Davis and other cities, at least in a coarse way.

\section{Statistical analysis}

We implement a Manifest Markov Model (see Vermunt and Magidson 2017) in the statistical software program Latent Gold 5.0. A Manifest Markov Model enables the estimation of the probability of belonging to a modality type, the transition probability of switching modality types over time, and the response probability measuring the influence of the latent variable on survey indicators (i.e. number of days traveled with a specific mode). This type of model is well suited for answering our research questions because it assesses membership and transition probabilities in one model. We are particularly interested in the effect of changes in different life domains on changes in travel behavior. Another modeling approach, for instance a multinomial logit model, would require 12 categories of switching between modality types and 4 categories of loyal ones. Manifest Markov Models allow us to directly estimate transition probabilities of switching modality types considering life events and life stage at the same time, an advantage over multinomial logit models. The Manifest Markov Model also differs from a Latent Markov Model $^{1}$ (also known as a

\footnotetext{
1 The Latent Markov Model calculates the probability that an individual chooses a response from a categorical variable (observed/survey data) based on three probabilities: the initial probability of choosing a modality type at time point 1 (membership probability), the transition probabilities, and the response probability for an individual i at time t. Latent Markov Model: (cf. Vermunt and Magidson 2016, pp. 92-93):

$$
P\left(y_{i}\right)=\sum_{x_{0}^{d}=1}^{K^{d}} \sum_{x_{1}^{d}=1}^{K^{d}} \cdots \sum_{x_{T}^{d}=1}^{K^{d}} P\left(x_{0}^{d}\right) \prod_{t=1}^{T_{i}} P\left(x_{t}^{d} \mid x_{t-1}^{d}\right) \prod_{t=0}^{T_{i}} P\left(y_{i t} \mid x_{t 1}^{d}\right)
$$

The probability of choosing response y for individual i is defined by the probability to choose a latent state (in our case a modality type) at time point $0 P\left(x_{0}^{d}\right)$, by the transition probability $P\left(x_{t}^{d} \mid x_{t-1}^{d}\right)$ and the response probability $P\left(y_{t}^{d} \mid x_{t}^{d}\right)$. A Latent Markov Model assumes that state membership at point $\mathrm{t}$ only depends on state membership of the previous period ( $\mathrm{t}-1$ ) (first order Markov assumption) (Vermunt and Magidson 2016). The response at point $t$ depends only on the current modality type membership not on previous ones.
} 


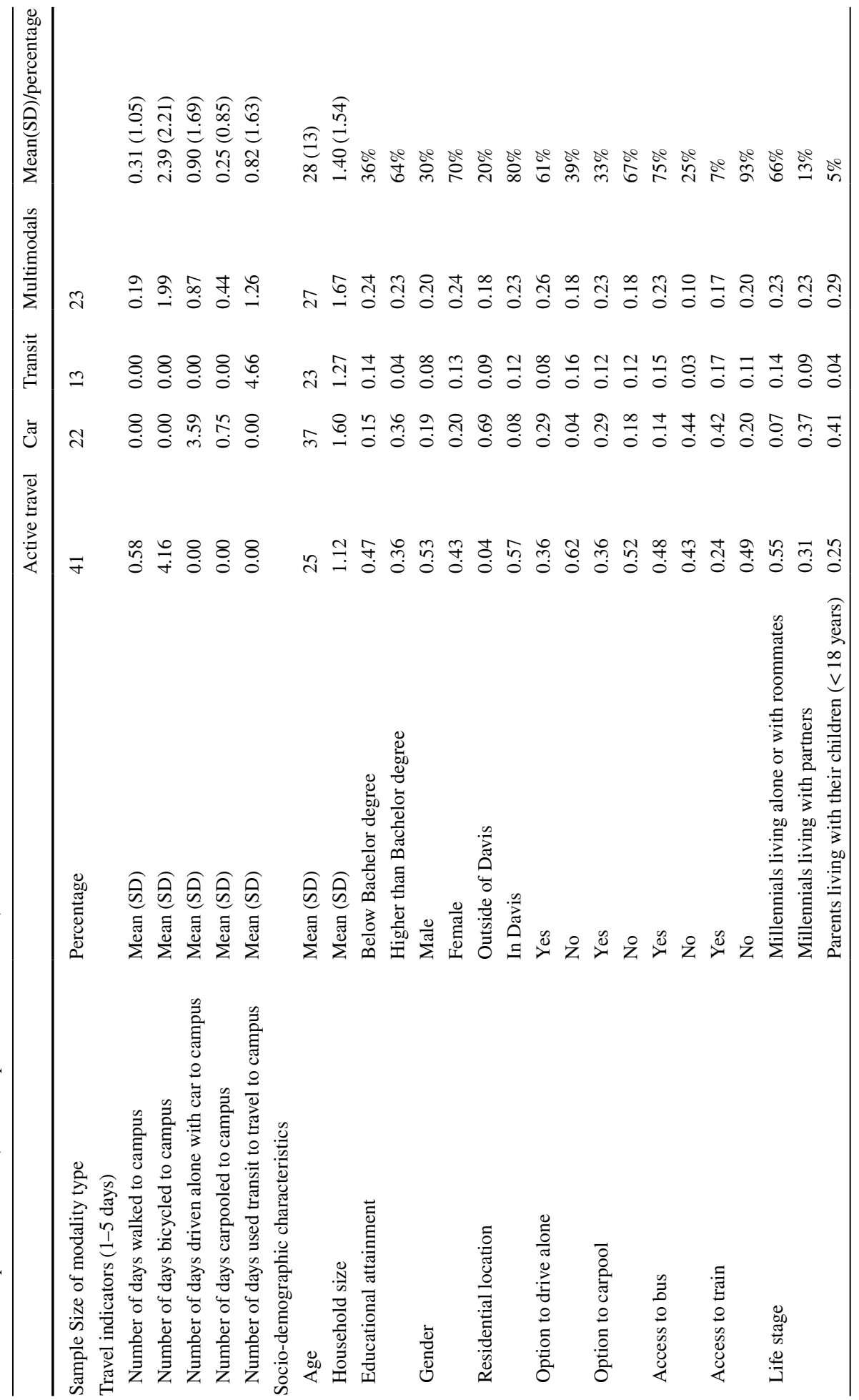




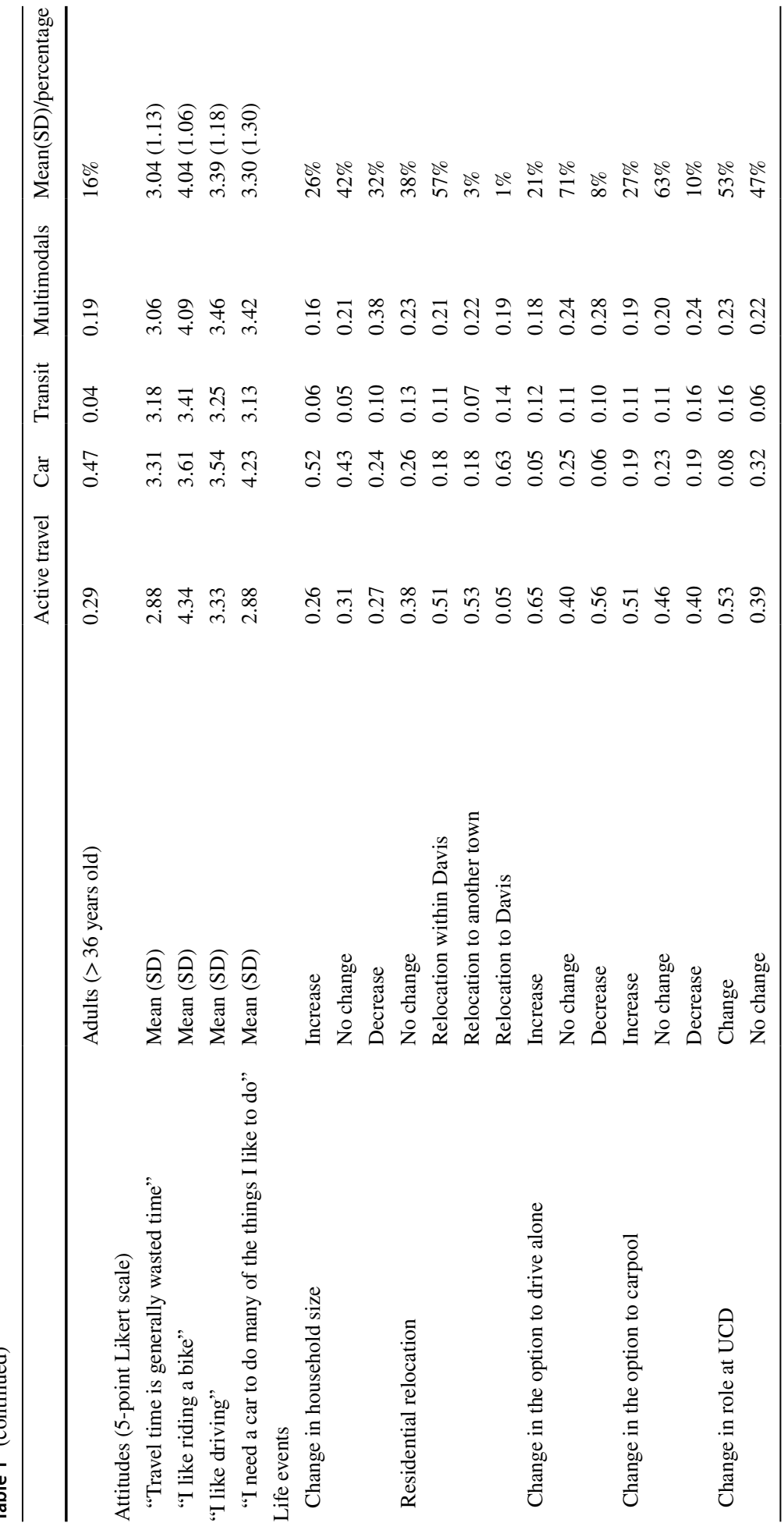


latent transition analysis), with which readers may be more familiar. In contrast to a Latent Markov Model, by using a Manifest Markov Model we assume that observed categorical responses (on transport mode choice) are deterministic measures of the true "latent" states (modality types). By using deterministic modality types, we assume that the response probability $P\left(y_{t}^{d} \mid x_{t}^{d}\right)$ is one for the modality type an individual is classified in and zero for other modality types. The probability of being in a modality type is modelled as a standard logistic regression while the transition model is estimated via a transition logit model (Vermunt and Magidson 2016). ${ }^{2}$ This Manifest Markov Model is extended so that the membership and transition probabilities include covariates, life stage groups and life events.

In specifying the model, we first estimate the influence of covariates (socio-demographic characteristics, travel-related attitudes) on our deterministic modality types. All covariates in the membership equation interact with life stage. Second, the transition probability depends on life events that interact with life stage and the previous modality type. It also includes a time interval variable interacting with the previous modality type (but not with life stage). The time interval variable measures the distance between the reported periods, to account for the fact that $32 \%$ of the persons answered their second survey at a later point than 1 year after the first; this is a recommended approach for accounting for heterogeneity in response intervals (cf. Markov Model with time-heterogeneous effects, Vermunt and Magidson 2015).

Our first research question asks whether life events lead to changes in modality types. Our second research question asks whether life stage moderates the impact of life events on change in modality types. We estimate two models. In the first model, life events interact with life stage and previous modality type in the transition probability model. In the second model, life events only interact with the previous modality type and not with life stage in the transition probability model. We compare both models based on the likelihood ratio test and the $p$ value. However, model comparison based on the likelihood ratio Chi squared statistic and $p$ values do not hold in the case of sparse data (Vermunt and Magidson 2015, p. 107). Our model includes 732 parameters with the conditional effect of life stage and 336 without the conditional effect of life stage. Although our panel is a considerable size with 6942 points of observations, we may still have sparsity problems due to the three-way interaction of life events, life stage and previous modality types. We use the Bayesian Information Criterium (BIC) as suggested by Vermunt and Magidson (2015, p. 107) in the case of sparse data. Kroesen (2014) also used the BIC due to data sparsity to compare different models in a latent class transition analysis. The model without the interaction effect of life stages in the transition probability provided a lower, better BIC $(-12963)$ than the model with conditional life stage effect $(-10217)$. In addition, almost all interaction effects between life events and life stages in the transition probability were insignificant. Based on these two factors, we chose the model without conditional life stage effect because it

2 Transition Logit Model:

$$
\log \frac{P\left(x_{t}^{d}=s \mid x_{t-1}^{d}=r, x, z_{i t}\right)}{P\left(x_{t}^{d}=r \mid x_{t-1}^{d}=r, x, z_{i t}\right)}=\gamma_{x r s 0}+\sum_{p=1}^{P} \gamma_{x r s p} * z_{i t p}
$$

The transition logit model calculates the ratio of the probability of switching from one modality type to another and the probability of not switching at all. The transition logit model compares the probabilities of switching to the probability of staying in the same latent state (modality type) with $r$ standing for the original and s for the destination state (modality type) and $\mathrm{r}$ unequal s since parameters for no transition are fixed to zero for identification (cf. Vermunt and Magidson 2016, pp. 92-93). 
performs better in terms of parsimony and expected out-of-sample predictive ability. This may not be a definitive assessment of a potential moderating effect of life stage, however. In the following section, we provide results for the model that includes only life events to explain transitioning from one modality type to another.

Table 1 shows descriptive statistics for the variables included in the membership and transition models for the first wave.

\section{Results}

Our findings support the results of other studies that observe a relationship between the occurrence of life events and changes in travel behavior. In this section, we first characterize the modality types and describe the incidence of life events in relation to life stage. Second, we present results from the membership model that highlight modality type profiles for different life stages. Finally, we explore the effect of life events on modality types.

\section{Descriptive statistics}

\section{Modality types}

Socio-economic characteristics and attitudes differ in significant and largely predictably ways between the four modality types (active travelers, car users, transit users, and multimodal travelers) (Table 1). Active travelers mostly bicycled to campus and walked only to a small extent. Likewise, car users mostly drove alone by car and only carpooled to a small extent. Multimodal travelers mostly bicycled (on average 2 days) and used transit to travel to campus but also drove alone by car to the university to a small extent.

\section{Modality types and life stage}

The share of active travelers decreases over the life stages but is the smallest for parents who live with their children (Fig. 2). Half of the millennials who lived alone, in a dorm, or in a shared apartment are active travelers. The share of persons who carpooled or drove alone to campus increases sharply when millennials start living with their partners and further increases throughout the life stages. The share of persons in the multimodal modality type is approximately equal across life stage groups; the use of different modes does not seem to depend on life stage. Non-millennial adults living without their children have the highest share of car users. Transit use decreases for older life stage groups.

As highlighted in Fig. 3, the incidence of life events differed between life stage groups. Millennials who lived alone, in a dorm, or in a shared apartment were more likely to change their residence than other groups. More specifically, millennials living with their partners or parents living with children relocated more often than other life stage groups to another town. Only a small fraction in each group relocated to Davis from outside the city. Parents who lived with children were the most likely to change household size, which may relate to the birth of children, marriage, separation, or divorce, or children moving out of the house. Parents living with children and non-millennial adults had more consistent access to driving alone compared to their younger counterparts. Millennials living alone or in a shared apartment switched their position or role at UC Davis more often. 


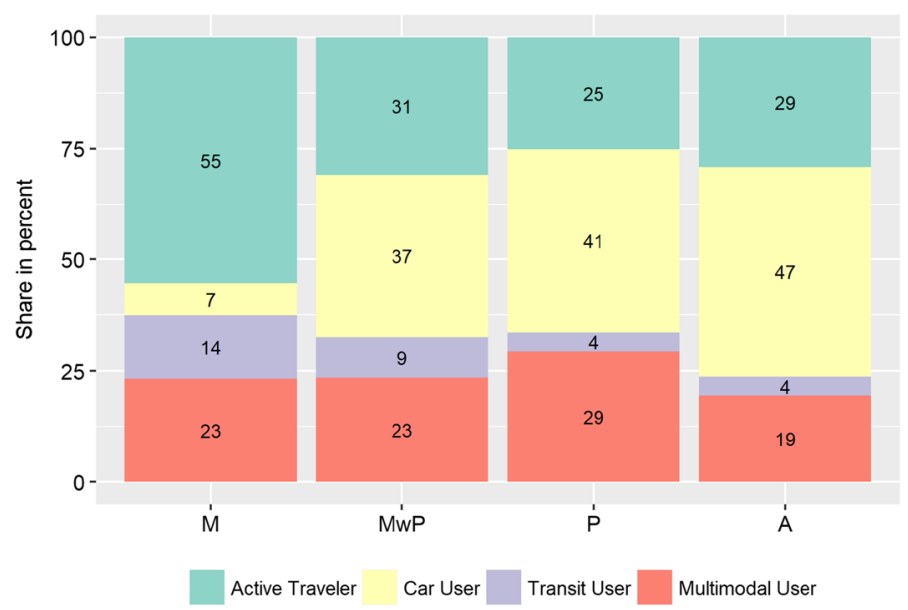

Fig. 2 Distribution of modality types across life stage groups. Life stages: $M$ "millennials living alone or shared apartments", $M w P$ "millennials living with their partners", $P$ "parents living with their children"; and $A$ "adults older than 36 years living without their children"

\section{Results from the membership model: differences in modality type profiles between life stages}

This section shows the results from the membership model for modality types. The results of the membership model suggest that socio-demographic and attitudinal characteristics determine modality type and have a different impact depending on the life stage. In the model, we specified all constants and covariates for the modality type membership model to be conditional on the life stage. Almost all interaction effects between covariates and life stage are significant. Table 2 shows the results of the membership model, i.e. the estimated probabilities to be in a specific modality type, summarizing the shares and mean values for each covariate-life stage interaction with the corresponding $p$ values in parentheses. Table 4 shows the parameter estimates for the membership model and indicates whether a response pattern (an interaction between a covariate and life stage) differs significantly between modality types. In this section, we discuss the results of the membership model based on Table 2.

\section{Gender differences}

Gender differences are the greatest for active travelers in comparison to other modes. More men travel with active modes than women. Gender differences seem to be linked to life stage: the share of female active travelers decreases over the life stages. Women and men are almost equally represented in the active traveler group when they are still millennials who live alone, in a dorm, or in shared apartment. For parents who live with their children or non-millennials, the share of male active travelers is twice as high as the share of women. Also, women are more likely than men to drive or carpool when they live with their children. In general, gender-differences stand out for parents and non-millennials across all modality types. These results suggest that gender disparities increase over the life cycle but may also indicate that millennials may behave differently than older generations in fundamental ways. 


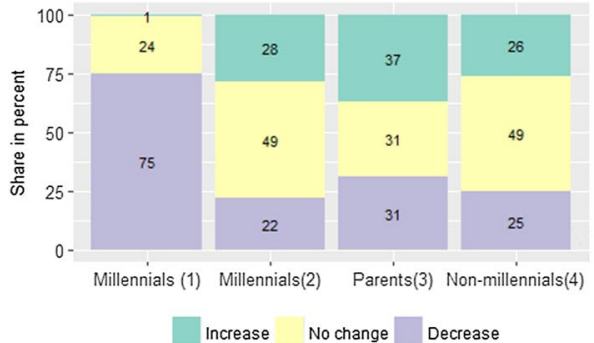

(a)

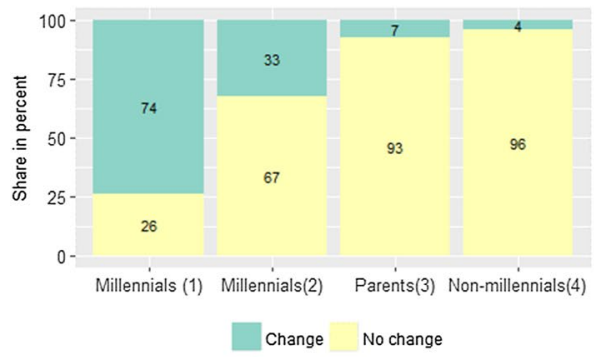

(c)

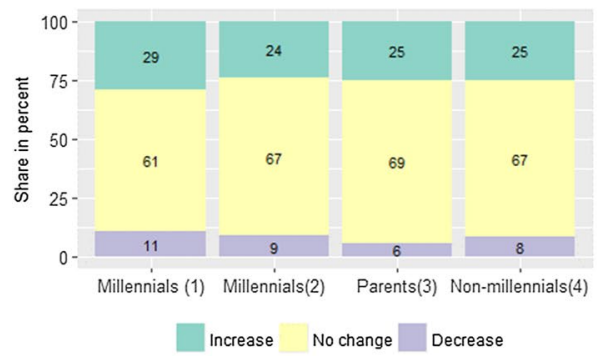

(e)

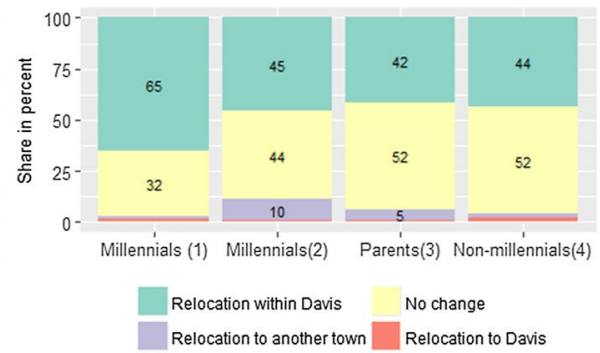

(b)

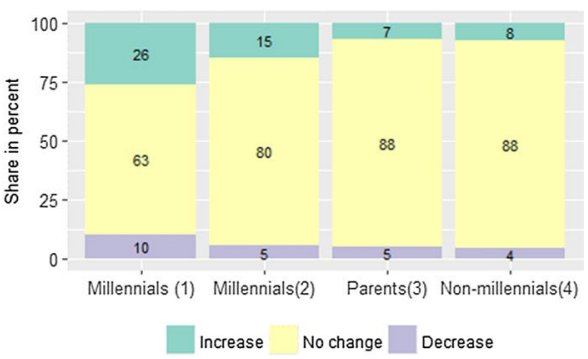

(d)

Fig. 3 Percentage of persons who experienced a life event out of the total sample per life stage group. Life events: a changes in household size, b changes in residential location, $\mathrm{c}$ changes in role at UCD, $d$ changes in the option to drive alone, e changes in the option to carpool, life stages: millennials $(1)=$ "millennials living alone or shared apartments", millennials $(2)=$ "millennials living with their partners", parents $(3)=$ "parents living with their children"; and non-millennials $(4)=$ "adults older than 36 years living without their children"

\section{Residential location}

The share of persons who only use a car to travel to campus is considerably higher for those living outside of Davis across all life stage groups. ${ }^{3}$ This difference is slightly more pronounced for millennials living alone, in dorms, or in shared apartments and for

\footnotetext{
${ }^{3}$ A small percentage of persons walked or bicycled to campus although they live outside of Davis. These persons provided a different usual mode to travel to campus indicating that in the reporting week they may have stayed in Davis and hence could walk or bicycle to UC Davis.
} 
Table 2 Modality type profiles and differences between life stages based on the membership model

\begin{tabular}{|c|c|c|c|c|c|}
\hline & & Active travelers & Car users & Transit users & $\begin{array}{l}\text { Multi- } \\
\text { modal } \\
\text { travelers }\end{array}$ \\
\hline Class size & & 1432 & 770 & 461 & 808 \\
\hline \multicolumn{6}{|l|}{ Indicator variables (mean) } \\
\hline \# of days walked & & 0.6 & 0.0 & 0.0 & 0.2 \\
\hline \# of days bicyclied & & 4.2 & 0.0 & 0.0 & 2.0 \\
\hline \# of days driven alone & & 0.0 & 3.6 & 0.0 & 0.9 \\
\hline \# of days carpooled & & 0.0 & 0.8 & 0.0 & 0.4 \\
\hline$\#$ of days used transit & & 0.0 & 0.0 & 4.7 & 1.3 \\
\hline \multirow[t]{4}{*}{ Life stage group $(p=0.00)$} & $\mathrm{M}$ & $55 \%$ & $7 \%$ & $14 \%$ & $23 \%$ \\
\hline & MwP & $31 \%$ & $37 \%$ & $9 \%$ & $23 \%$ \\
\hline & $\mathrm{P}$ & $25 \%$ & $41 \%$ & $4 \%$ & $29 \%$ \\
\hline & A & $29 \%$ & $47 \%$ & $4 \%$ & $19 \%$ \\
\hline \multirow[t]{4}{*}{ Age $(p=0.00)$} & M & 21 & 24 & 21 & 21 \\
\hline & MwP & 26 & 26 & 25 & 26 \\
\hline & $\mathrm{P}$ & 46 & 42 & 42 & 42 \\
\hline & $\mathrm{A}$ & 53 & 50 & 52 & 51 \\
\hline \multicolumn{6}{|l|}{ Gender $(p=0.00)$} \\
\hline Male & M & $65 \%$ & $5 \%$ & $10 \%$ & $20 \%$ \\
\hline Female & M & $52 \%$ & $8 \%$ & $16 \%$ & $24 \%$ \\
\hline Male & MwP & $37 \%$ & $35 \%$ & $8 \%$ & $19 \%$ \\
\hline Female & MwP & $27 \%$ & $38 \%$ & $9 \%$ & $26 \%$ \\
\hline Male & $\mathrm{P}$ & $33 \%$ & $29 \%$ & $7 \%$ & $31 \%$ \\
\hline Female & $\mathrm{P}$ & $17 \%$ & $53 \%$ & $2 \%$ & $28 \%$ \\
\hline Male & A & $43 \%$ & $36 \%$ & $6 \%$ & $15 \%$ \\
\hline Female & A & $18 \%$ & $55 \%$ & $3 \%$ & $23 \%$ \\
\hline \multirow[t]{4}{*}{ Household size $(p<0.03)$} & M & 3.5 & 3.5 & 3.8 & 3.3 \\
\hline & MwP & 1.9 & 2.0 & 1.9 & 2.1 \\
\hline & $\mathrm{P}$ & 2.7 & 2.2 & 2.8 & 2.9 \\
\hline & A & 1.7 & 1.7 & 1.5 & 1.7 \\
\hline \multicolumn{6}{|l|}{ Residential location $(p<0.00)$} \\
\hline Residence in Davis & M & $58 \%$ & $5 \%$ & $14 \%$ & $23 \%$ \\
\hline Residence outside of Davis & M & $4 \%$ & $70 \%$ & $1 \%$ & $24 \%$ \\
\hline Residence in Davis & MwP & $55 \%$ & $11 \%$ & $5 \%$ & $28 \%$ \\
\hline Residence outside of Davis & MwP & $4 \%$ & $66 \%$ & $14 \%$ & $16 \%$ \\
\hline Residence in Davis & $\mathrm{P}$ & $43 \%$ & $21 \%$ & $1 \%$ & $35 \%$ \\
\hline Residence outside of Davis & $\mathrm{P}$ & $4 \%$ & $67 \%$ & $8 \%$ & $21 \%$ \\
\hline Residence in Davis & $\mathrm{A}$ & $50 \%$ & $25 \%$ & $1 \%$ & $24 \%$ \\
\hline Residence outside of Davis & $\mathrm{A}$ & $3 \%$ & $72 \%$ & $8 \%$ & $17 \%$ \\
\hline \multicolumn{6}{|c|}{ Option to drive alone $(p<0.00)$} \\
\hline 0 & M & $64 \%$ & $1 \%$ & $17 \%$ & $18 \%$ \\
\hline 1 & M & $46 \%$ & $14 \%$ & $11 \%$ & $29 \%$ \\
\hline 0 & MwP & $52 \%$ & $13 \%$ & $16 \%$ & $19 \%$ \\
\hline 1 & MwP & $26 \%$ & $42 \%$ & $8 \%$ & $24 \%$ \\
\hline 0 & $\mathrm{P}$ & $40 \%$ & $30 \%$ & $5 \%$ & $25 \%$ \\
\hline
\end{tabular}


Table 2 (continued)

\begin{tabular}{|c|c|c|c|c|c|}
\hline & & Active travelers & Car users & Transit users & $\begin{array}{l}\text { Multi- } \\
\text { modal } \\
\text { travelers }\end{array}$ \\
\hline 1 & $\mathrm{P}$ & $23 \%$ & $42 \%$ & $4 \%$ & $30 \%$ \\
\hline 0 & A & $42 \%$ & $40 \%$ & $8 \%$ & $10 \%$ \\
\hline 1 & A & $28 \%$ & $48 \%$ & $4 \%$ & $20 \%$ \\
\hline \multicolumn{6}{|l|}{ Option to carpool $(p<0.00)$} \\
\hline 0 & M & $61 \%$ & $6 \%$ & $14 \%$ & $19 \%$ \\
\hline 1 & M & $45 \%$ & $13 \%$ & $15 \%$ & $27 \%$ \\
\hline 0 & MwP & $33 \%$ & $39 \%$ & $9 \%$ & $19 \%$ \\
\hline 1 & MwP & $29 \%$ & $45 \%$ & $9 \%$ & $17 \%$ \\
\hline 0 & $\mathrm{P}$ & $29 \%$ & $46 \%$ & $6 \%$ & $19 \%$ \\
\hline 1 & $\mathrm{P}$ & $14 \%$ & $64 \%$ & $0 \%$ & $23 \%$ \\
\hline 0 & A & $37 \%$ & $43 \%$ & $4 \%$ & $16 \%$ \\
\hline 1 & A & $15 \%$ & $68 \%$ & $5 \%$ & $11 \%$ \\
\hline \multicolumn{6}{|l|}{ Access to bus $(p<0.00)$} \\
\hline 0 & M & $72 \%$ & $19 \%$ & $1 \%$ & $8 \%$ \\
\hline 1 & M & $52 \%$ & $6 \%$ & $17 \%$ & $25 \%$ \\
\hline 0 & MwP & $19 \%$ & $65 \%$ & $7 \%$ & $9 \%$ \\
\hline 1 & MwP & $39 \%$ & $27 \%$ & $11 \%$ & $24 \%$ \\
\hline 0 & $\mathrm{P}$ & $19 \%$ & $67 \%$ & $3 \%$ & $11 \%$ \\
\hline 1 & $\mathrm{P}$ & $29 \%$ & $36 \%$ & $6 \%$ & $29 \%$ \\
\hline 0 & A & $18 \%$ & $67 \%$ & $3 \%$ & $12 \%$ \\
\hline 1 & A & $37 \%$ & $42 \%$ & $5 \%$ & $16 \%$ \\
\hline \multicolumn{6}{|l|}{ Access to train $(p<0.00)$} \\
\hline 0 & M & $19 \%$ & $67 \%$ & $3 \%$ & $11 \%$ \\
\hline 1 & M & $29 \%$ & $36 \%$ & $6 \%$ & $29 \%$ \\
\hline 0 & $\mathrm{MwP}$ & $18 \%$ & $67 \%$ & $3 \%$ & $12 \%$ \\
\hline 1 & MwP & $37 \%$ & $42 \%$ & $5 \%$ & $16 \%$ \\
\hline 0 & $\mathrm{P}$ & $55 \%$ & $8 \%$ & $15 \%$ & $22 \%$ \\
\hline 1 & $\mathrm{P}$ & $62 \%$ & $13 \%$ & $1 \%$ & $23 \%$ \\
\hline 0 & A & $37 \%$ & $39 \%$ & $5 \%$ & $19 \%$ \\
\hline 1 & A & $5 \%$ & $52 \%$ & $30 \%$ & $14 \%$ \\
\hline \multirow[t]{4}{*}{ Disutility of travel time $(p=0.00)$} & M & 2.9 & 3.4 & 3.3 & 3.1 \\
\hline & MwP & 2.7 & 3.6 & 3.0 & 3.1 \\
\hline & $\mathrm{P}$ & 3.1 & 3.4 & 2.1 & 2.8 \\
\hline & A & 2.8 & 3.1 & 2.3 & 3.0 \\
\hline \multirow[t]{4}{*}{ Liking of bicycling $(p=0.00)$} & M & 4.3 & 3.3 & 3.3 & 4.1 \\
\hline & MwP & 4.3 & 3.6 & 4.0 & 4.0 \\
\hline & $\mathrm{P}$ & 4.4 & 3.9 & 4.4 & 4.1 \\
\hline & A & 4.7 & 3.7 & 3.8 & 4.3 \\
\hline \multirow[t]{4}{*}{ Liking of car driving $(p=0.00)$} & M & 3.4 & 3.7 & 3.4 & 3.6 \\
\hline & MwP & 2.9 & 3.4 & 3.1 & 3.3 \\
\hline & $\mathrm{P}$ & 3.0 & 3.6 & 2.6 & 3.6 \\
\hline & A & 2.9 & 3.5 & 2.4 & 3.1 \\
\hline Perceived need of a car $(p=0.00)$ & M & 2.8 & 4.3 & 3.1 & 3.3 \\
\hline
\end{tabular}


Table 2 (continued)

\begin{tabular}{cccccc}
\hline & Active travelers & Car users & Transit users & $\begin{array}{l}\text { Multi- } \\
\text { modal } \\
\text { travelers }\end{array}$ \\
\hline MwP & 3.0 & 4.3 & 3.1 & 3.6 \\
$\mathrm{P}$ & 3.5 & 4.3 & 2.9 & 3.8 \\
$\mathrm{~A}$ & 2.8 & 4.1 & 3.1 & 3.7 \\
\hline
\end{tabular}

Life stages: $M$ "millennials living alone or shared apartments", $M w P$ "millennials living with their partners", $P$ "parents living with their children", $A$ "adults older than 36 years living without their children"

The value in parentheses behind covariates indicates the $p$ value for the Wald test statistic assessing the statistical significance of a set of parameter estimates for one indicator

non-millennials. Millennials who live outside of Davis and with their partners have a higher share of transit use than other life stage groups. Millennials who live alone or in shared apartments and outside of Davis have the highest share of multimodal users compared to other life stage groups. Persons of the first life stage group who live outside of Davis like biking and driving slightly less than persons of other life stage groups who live outside of Davis.

\section{Attitudinal statements}

Across all life stage groups, car users agree more strongly with the statement "Travel time is generally wasted time." Parents and non-millennials who use transit to travel to campus have the lowest agreement with this statement. Active and multimodal travelers appreciate bicycling the most, with non-millennials scoring highest. Millennials who live without children or a partner and use transit agree more with the statement "I like driving" while non-millennials are rather neutral. Car users reported the highest agreement with the statement "I need a car to do many of the things I like to do." Members of the second, third, and fourth life stage groups who are multimodal tend to have a higher agreement, too. Parents in general have a higher agreement with this statement except when they use transit.

\section{Loyalty to modality types and the influence of life events}

Transition probabilities in Table 3 describe the probability of switching from one modality type to another from one year to the next. The reference level is individuals who do not experience any life event. For instance, it is less likely for active travelers to switch to multimodal use if the household size decreases or increases compared to active travelers who do not experience any change in household size. A decrease in household size makes a switch from strict car use to active travel less likely.

Almost all constants are significant and negative, indicating that travel behavior tends to be stable (Table 3). In particular, persons who only drive alone or carpool to campus (car users) tend to stick with their modality type with a probability of $83 \%$ (Table 3 ). This suggests that driving may be a stronger habitual behavior than other travel patterns. Multimodal travelers are rather unstable and have the highest probability of switching to active travel but also to car use compared to other modality types. Residential relocation within 
Table 3 Comparing transition probabilities between modality types and from wave 1 (rows) to wave 2 (columns) in the presence of life events. (Color table online)

\begin{tabular}{|c|c|c|c|c|}
\hline & 1 & 2 & 3 & 4 \\
\hline 1 & 0.59 & 0.06 & 0.12 & 0.23 \\
\hline 2 & 0.06 & 0.83 & 0.03 & 0.08 \\
\hline 3 & 0.15 & 0.08 & 0.52 & 0.25 \\
\hline 4 & 0.28 & 0.22 & 0.13 & 0.37 \\
\hline \multicolumn{5}{|c|}{ Decrease in household size } \\
\hline
\end{tabular}

\begin{tabular}{lcccc}
\hline & 1 & 2 & 3 & 4 \\
\hline 1 & 0.67 & 0.13 & 0.06 & 0.14 \\
2 & 0.06 & 0.74 & 0.11 & 0.10 \\
3 & 0.15 & 0.21 & 0.37 & 0.27 \\
4 & 0.24 & 0.39 & 0.10 & 0.27 \\
\multicolumn{4}{l}{ No change in residence } \\
\hline
\end{tabular}

No change in household size

\begin{tabular}{cccc}
\hline 1 & 2 & 3 & 4 \\
\hline 0.59 & 0.08 & 0.06 & 0.27 \\
0.10 & 0.79 & 0.03 & 0.08 \\
0.04 & 0.25 & 0.51 & 0.19 \\
0.24 & 0.38 & 0.06 & 0.33
\end{tabular}

Relocating within Davis

\begin{tabular}{cccc}
\hline 1 & 2 & 3 & 4 \\
\hline 0.60 & 0.06 & 0.10 & 0.24 \\
0.07 & 0.77 & 0.04 & 0.12 \\
0.16 & 0.14 & 0.46 & 0.23 \\
0.29 & 0.29 & 0.12 & 0.30
\end{tabular}

No change in role at UCD

\begin{tabular}{cccc}
\hline 1 & 2 & 3 & 4 \\
\hline 0.68 & 0.13 & 0.03 & 0.16 \\
0.05 & 0.80 & 0.05 & 0.10 \\
0.10 & 0.19 & 0.46 & 0.25 \\
0.21 & 0.42 & 0.04 & 0.33
\end{tabular}

No change in access to DA

\begin{tabular}{cccc}
\hline 1 & 2 & 3 & 4 \\
\hline 0.61 & 0.14 & 0.07 & 0.18 \\
0.08 & 0.79 & 0.03 & 0.10 \\
0.12 & 0.20 & 0.46 & 0.23 \\
0.21 & 0.40 & 0.07 & 0.32
\end{tabular}

No change in access to carpool

\begin{tabular}{cccc}
\hline 1 & 2 & 3 & 4 \\
\hline 0.59 & 0.15 & 0.07 & 0.19 \\
0.06 & 0.75 & 0.07 & 0.12 \\
0.09 & 0.25 & 0.42 & 0.24 \\
0.29 & 0.27 & 0.09 & 0.35
\end{tabular}

\begin{tabular}{cccc}
\multicolumn{4}{l}{ Increase in household size } \\
\hline 1 & 2 & 3 & 4 \\
\hline 0.68 & 0.12 & 0.07 & 0.14 \\
\hline 0.04 & 0.80 & 0.04 & 0.12 \\
0.15 & 0.08 & 0.54 & 0.23 \\
0.26 & 0.28 & 0.08 & 0.38
\end{tabular}

Relocating to another city

\begin{tabular}{cccc}
\hline 1 & 2 & 3 & 4 \\
\hline 0.05 & 0.71 & 0.17 & 0.07 \\
0.01 & 0.72 & 0.11 & 0.17 \\
0.00 & 0.98 & 0.02 & 0.00 \\
0.03 & 0.73 & 0.07 & 0.18
\end{tabular}

Change in role at $\mathrm{UCD}$

\begin{tabular}{cccc}
\hline 1 & 2 & 3 & 4 \\
\hline 0.52 & 0.13 & 0.14 & 0.21 \\
0.11 & 0.64 & 0.10 & 0.15 \\
0.17 & 0.23 & 0.41 & 0.19 \\
0.29 & 0.22 & 0.19 & 0.30
\end{tabular}

Increase in access to DA

\begin{tabular}{cccc}
\hline 1 & 2 & 3 & 4 \\
\hline 0.54 & 0.20 & 0.08 & 0.18 \\
0.06 & 0.74 & 0.11 & 0.10 \\
0.13 & 0.33 & 0.38 & 0.16 \\
0.23 & 0.23 & 0.16 & 0.39
\end{tabular}

Increase in access to carpool

\begin{tabular}{cccc}
\hline 1 & 2 & 3 & 4 \\
\hline 0.57 & 0.14 & 0.10 & 0.19 \\
0.06 & 0.76 & 0.05 & 0.13 \\
0.15 & 0.23 & 0.40 & 0.21 \\
0.23 & 0.33 & 0.09 & 0.35
\end{tabular}

\begin{tabular}{cccccccc}
\multicolumn{2}{l}{ Time interval of 3 years } & \multicolumn{7}{c}{ Time interval $>3$ years } \\
\hline 1 & 2 & 3 & 4 & 1 & 2 & 3 & 4 \\
\hline 0.62 & 0.13 & 0.08 & 0.17 & 0.56 & 0.21 & 0.03 & 0.20 \\
0.02 & 0.86 & 0.00 & 0.12 & 0.05 & 0.81 & 0.00 & 0.14 \\
0.23 & 0.26 & 0.19 & 0.32 & 0.00 & 0.43 & 0.57 & 0.00 \\
0.17 & 0.41 & 0.10 & 0.32 & 0.21 & 0.58 & 0.00 & 0.21
\end{tabular}

Modality types: 1 active travelers, 2 car users, 3 transit users, 4 multimodal travelers. Grey cells indicate a significant increase in the probability to switch from one to another modality type and dark cells a decrease

Davis positively affects the probability of transitioning between modality types: from active travel to transit or multimodal travel, from car to multimodal travel and from transit to active travel. Relocating to another town makes a switch from active travel to car and transit travel more likely because the distance to the campus in most cases becomes too long for active modes. Likewise, switching from car use to multimodal travel and vice versa becomes more likely if persons relocate to another town. Relocating to Davis significantly 
reduces the probability of switching from multimodal to strict car use but increases the likelihood of switching from transit to active travel.

Persons who no longer have the option to drive alone in a car are also less likely to switch from active travel to strict car use whereas a switch from car or multimodal use to all other modes is more likely. An increase in the option to drive alone makes transitioning from active travel and transit to car use more likely. If carpool becomes unavailable, persons are more likely to switch from strict car use to active travel or from multimodal to transit. Persons who gain access to carpool are more likely to switch from transit to active travel. Transit users seem to be less affected by life events in general than other modality types.

Heterogeneity in the time interval in which respondents answered the survey affects the probability of transitioning to another mode. Table 3 shows the probabilities of switching to another modality type with a time interval of two, three and more than 3 years relative to a 1-year time interval. The probability of switching to strict car use significantly increases over time (with duration between two survey responses). With few exceptions, this significant increase appears only for strict car users. Loyalty to a modality type, other than strict car use, decreases over time.

\section{Discussion and conclusions}

Our first research question was the extent to which life events effect change in travel behavior. The results of this study highlight the importance of life events in explaining travel behavior change, specifically shifts in modality type. Residential relocation, changes in household size, changes in the option to drive alone or to carpool, and changes in role at UC Davis significantly affect the probability of switching between modality types. A move from Davis to another town, which necessarily means an increase in commute distance, is associated with a switch towards car, transit, or multimodal travel. Conversely, moving to Davis, which necessarily decreases commute distance, increases the chance of switching to active and multimodal travel. Transition may be explained in part by the fact that Davis has extensive bicycle infrastructure and a strong bicycling culture. However, only one percent of the sample actually relocated to Davis. Active travelers seem to be more affected by changes in household size, which is consistent with findings that the share of active travelers decreases throughout the life stages. For instance, previous research revealed that persons are likely to stop bicycling when they become a parent (Oakil et al. 2016).

Almost all modality types showed state dependence, meaning that modality type is more likely to not change than it is to change, though car users showed the highest behavior probability of staying loyal to their modality type. These results suggest a rigidity in travel once participants have adopted the modality type of car travel. Our results are consistent with Kroesen (2014) and De Haas et al. (2018), who found that unimodal users were more likely to stick to their modes than multimodal users. Interestingly, in our study, an increase in carpool access does not affect the probability of transitioning to another modality type (except for transit users switching to active travel) whereas an increase in the possibility of driving alone increased the probability for all respondents (except for multimodal travelers) of switching to strict car use. This result suggests that policies that incentivize carpool over driving alone may discourage strict car use and allow persons to reach destinations only accessible by car. In general, transit users seem to be less affected by life events than other modality types, which may indicate that transit users are captive riders and cannot freely switch between 
modes. Kroesen (2014) found that persons were more likely to switch to public transport when they also switched employment, a life event that we did not include in our analysis.

With our second research question, we investigated whether life events affect travel behavior differently at distinct life stages. Life stage did not moderate the effect of life events on travel behavior, as we had hypothesized. We propose several explanations for this result. This analysis considered the life stage situation of the first wave for the membership model although individuals may switch life stage groups by the second wave. In fact, life events may trigger a transition from one life stage to another, marking the beginning of a new life stage such as the birth of a child marking the beginning of parenthood. Previous studies highlight the interdependence of life events, life stage and travel behavior (e.g. Beige and Axhausen 2008; Zhang 2017). Life events and life stage may be correlated and not as distinguishable as our research questions suggests. This may explain some of the insignificant moderating effects of life stages in our study. Another explanation may relate to the fact that we mix generation and life stage since millennials can also be in the third life stage group. In addition, the three-way interaction of life stage, life event, and previous modality type may lead to insufficient variation in the data. For these reasons, this study is not a definitive test of the moderating effect of life stage on the impact of life events.

However, life stage did significantly influence membership in one of four modality types. Millennials living with partners or parents more often relocate to another town, possibly reflecting specific preferences for more space and comfort at this life stage as well as high housing prices in Davis. Pressures in the housing market may drive young couples or parents to locate in more car-dependent areas (Delbosc and Nakanishi 2017; Gehrke et al. 2019; Thierstein et al. 2016). Millennials who live alone or in shared apartments are more dynamic: they change their residence within Davis, their role at UC Davis and car availability more often than other life stage groups. This could reflect the fact that they are at the beginning of their career and experience more change with respect to their socioeconomic status and mobility resources, as supported by previous studies (Beige and Axhausen 2008; Dargay and Hanly 2004; Oakil et al. 2016). Life stage significantly affects active traveling and car use. The share of active travelers decreases over the life stages and is particularly low for parents. A possible explanation for this might be that it gets more difficult to combine the travel needs of other persons and professional responsibilities with active travel at this life stage (Oakil et al. 2016). Contrary to our hypothesis, all life stage groups have an approximately similar share of multimodal travelers; life stage seems to not affect multimodal travel. We acknowledge, however, that our sample is drawn from a university population and a university town that offers a greater variety in available transport modes and modal split compared to other small-sized US towns.

Another important finding is that gender differences play a role in explaining modality type membership and may also be linked to life events and life stage. The share of women who are active travelers decreases throughout the life stages, as also found in other studies (e.g. Scheiner 2014). Since we group respondents into life stages that also correspond to different generations it is not clear whether gender disparities increase over the life cycle or generational differences play a role in explaining gender disparities. If we split our sample into millennials with children and without children, female and male millennials without children are equally represented in the active travelers group while only a quarter of millennial active travelers with children are women. However, female non-millennials have the same share in the active traveler group regardless of their status of parenthood. This observation suggests that millennials may fall back into gender disparities of travel behavior of former generations when they become parents. These results support the argument of other studies that behavioral differences of millennials may be temporal and partly due to delayed life stage (Delbosc and Currie 2013). Since the numbers of observations in our dataset are 
relatively small in each category these results should be treated with caution and tested with a larger sample. Nevertheless, these results raise several questions for future research: Do millennials change their travel behavior to become more similar to non-millennials as they pass through the life cycle? More specifically, are gender disparities between millennials more or less pronounced compared to non-millennials as they move through the life cycle?

As pointed out in the literature, life events represent a potential "window of opportunity" for triggering changes in travel behavior. According to our results, it seems that this momentum for change is not moderated by the life stage of a person. Interventions might target recent movers or persons who change their household composition, regardless of life stage. Our results highlight that individuals tend to change their travel behavior after relocation. In particular, moving to locations at larger distance from the workplace was often associated with an increase in car use. These results put emphasis on the fact that residential and travel choices are interlinked and suggest that some transportation policies may be more effective if planned in accordance with housing policies. Also, policies that incentivize better use of mobility resources within and between households through sharing and pooling and discourage the purchase of an additional car may be more effective if targeted towards recent movers who may need a car for their commute. For example, providing this group with the possibility of borrowing a second car occasionally when needed may promote lower car ownership. Our results show that a considerable number of persons switched from strict car use to multimodal travel in the presence of life events, suggesting that multimodal travel might be a more promising strategy for reducing car use than attempts to shift commuters from driving entirely to another mode. Car users might be open to reducing car travel on some days and thus could be good targets for interventions that provide positive experiences with active modes. Several countries provide local programs fostering bicycling to work during the month of May and may provide starting points to encourage multimodal use and hence active travel (for the UK: European Cyclists' Federation 2019; for the US: Nordback 2014; League of American Bicyclists 2019). Policy programs that encourage multimodal travel may address a diverse population since multimodal travel seems to not depend on life stage, according to our results.

Further research on these questions is required since many travel surveys only capture the primary mode of transport and provide limited understanding about multimodal and intermodal behavior. This is also a limitation of this study since we asked for the primary mode to travel to campus on a given day and assessed multimodality based on the variety of selected modes over the week. Future studies could explore methods for more precisely measuring intermodal travel. Research on the motivation for multi- and intermodal travel, using qualitative as well as quantitative methods, could provide needed evidence to improve the effectiveness of travel demand management programs as well as transportation planning in general.

In this study we measure the effect of life events on travel behavior in most cases for a 1-year interval, although behavioral responses may require more or less time, and travel behavior may change several times between 2 years or even lead to changes in anticipation of future travel needs (e.g. car acquisition before a childbirth). Time-lagged effects in behavioral responses make it difficult to causally link life events to changes in travel behavior. Several studies raise the issue of the temporal dimension of life events, life stage, and behavioral response (e.g. Lanzendorf 2003, 2010; Holz-Rau and Scheiner 2015; Oakil et al. 2014) though only a few studies empirically consider time-lagged effects (Müggenburg et al. 2015). Most of the quantitative studies consider time-lagged effects of life events on car ownership (Dargay 2001; Oakil et al. 2014; Wang et al. 2018). The literature mentions several reasons to explain delayed effects of life events: learning and experience induce continuous change in a 
transition process (Holz-Rau and Scheiner 2015), financial or mental restrictions (Oakil et al. 2014; Wang et al. 2018), time constraints, persuasiveness of habits, inertia, high searching costs, uncertainty, and imperfect information (Dargay 2001). Others put emphasis on the idea that individuals constantly adapt their travel behavior (Scheiner et al. 2016).

Capturing time-lagged effects with quantitative data is methodologically challenging. Further research based on qualitative data may provide more precise information on temporal intervals that could help to inform survey design (e.g. retrospective and prospective questions) and improve quantitative data collection that would provide deeper insights into individuals' planning, adaptation, and delay in behavioral responses to life events and choices such as inertia, periods of change, and transitioning. In general, the mobility biography approach is useful in linking short-, medium-, and long-term decisions and in understanding the temporal dimension of travel-related choices.

Acknowledgements Open access funding provided by TU Wien (TUW). This work was supported by the OEAD (Grant No. ICM-2017-06196) through the Marietta Blau Grant which was funded by the Austrian Federal Ministry of Education, Science and Research. This paper is based on a conference presentation held at the Transportation Research Board Annual Meeting 2019.

Author's contribution JJ: study conception and design, analysis, interpretation of the results, draft manuscript, editing of final manuscript; CGT: study conception and design, data collection, analysis, interpretation of the results, editing of final manuscript. SH: study conception and design, data collection, interpretation of the results, editing of final manuscript.

\section{Compliance with ethical standards}

Conflict of interest On behalf of all authors, the corresponding author states that there is no conflict of interest.

Open Access This article is licensed under a Creative Commons Attribution 4.0 International License, which permits use, sharing, adaptation, distribution and reproduction in any medium or format, as long as you give appropriate credit to the original author(s) and the source, provide a link to the Creative Commons licence, and indicate if changes were made. The images or other third party material in this article are included in the article's Creative Commons licence, unless indicated otherwise in a credit line to the material. If material is not included in the article's Creative Commons licence and your intended use is not permitted by statutory regulation or exceeds the permitted use, you will need to obtain permission directly from the copyright holder. To view a copy of this licence, visit http://creativecommons.org/licenses/by/4.0/.

\section{Appendix}

The parameter estimates in Table 4 indicate the probability to be in one of the three modality types (car, transit users, or multimodal travelers) instead of being in the active traveler modality type conditional on the specific life stage-covariate interaction. For instance, female millennials who lived alone, in a dorm, or in shared apartments have a higher probability than male millennials to be strict car users instead of being in the active traveler group. Millennials who were strict car users and lived with their partner were more likely to agree with the statement "Travel time is generally wasted time" (Disutility of travel time) compared to active traveling millennials living with their partner.

See Table 5. 


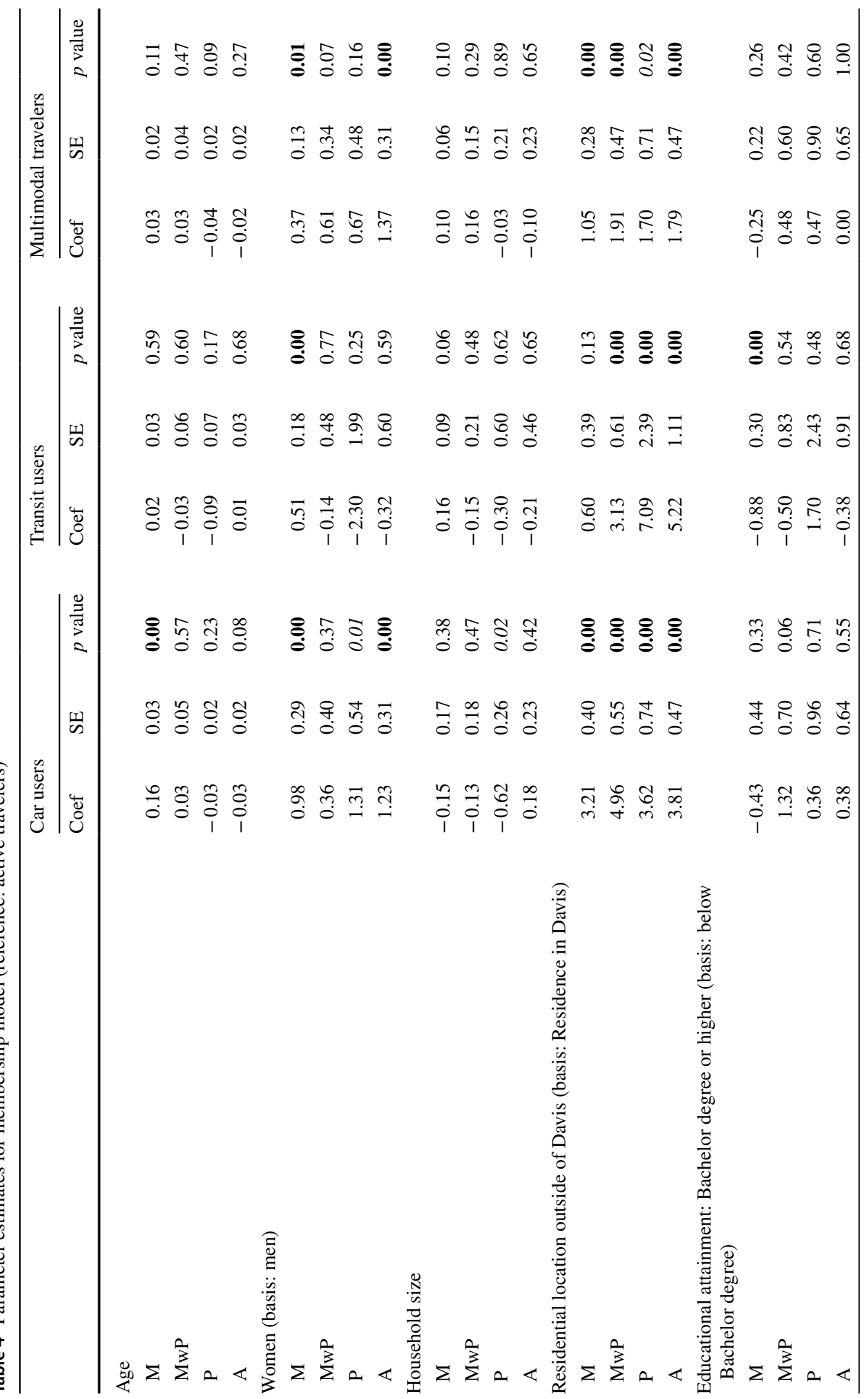




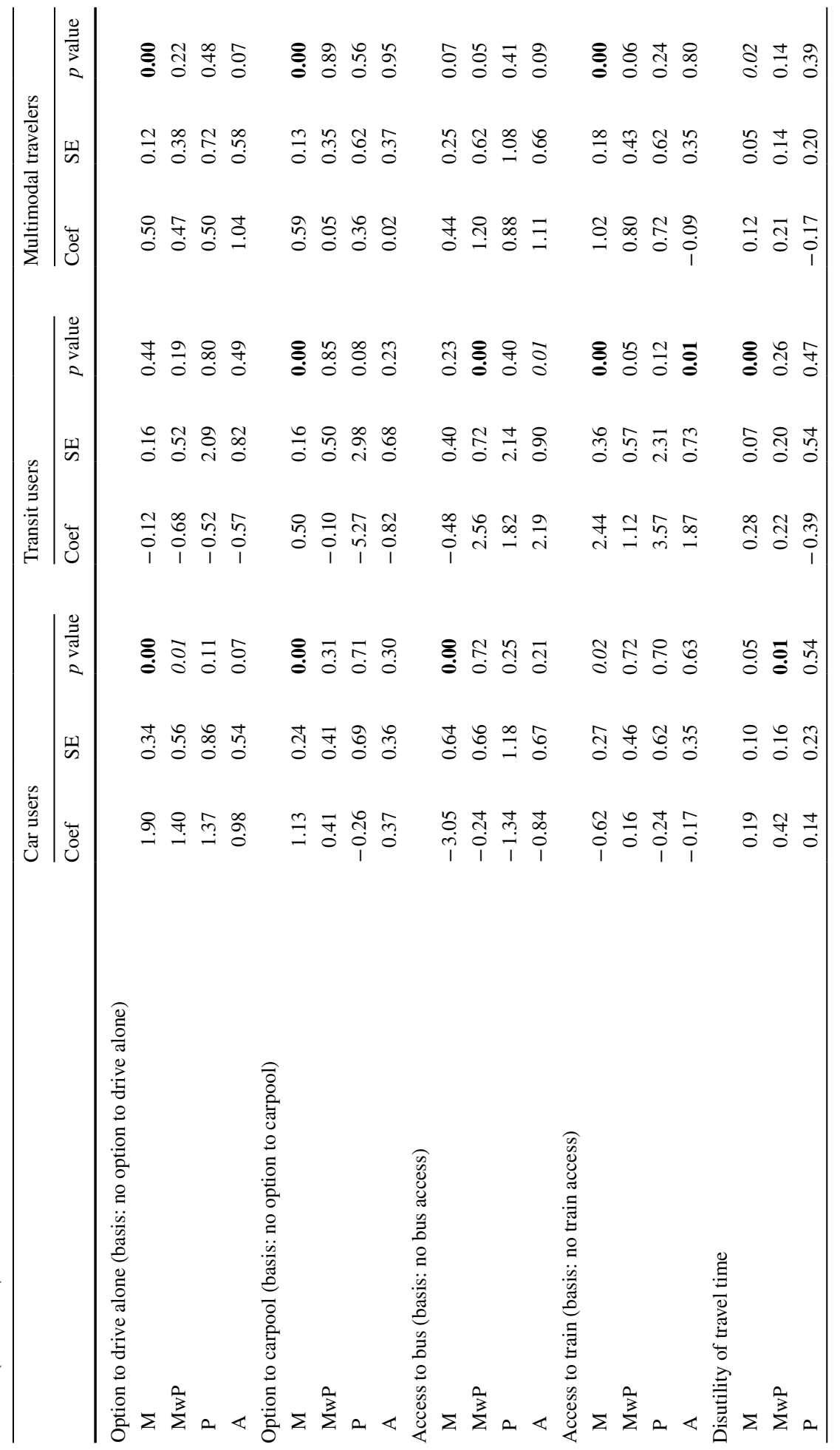




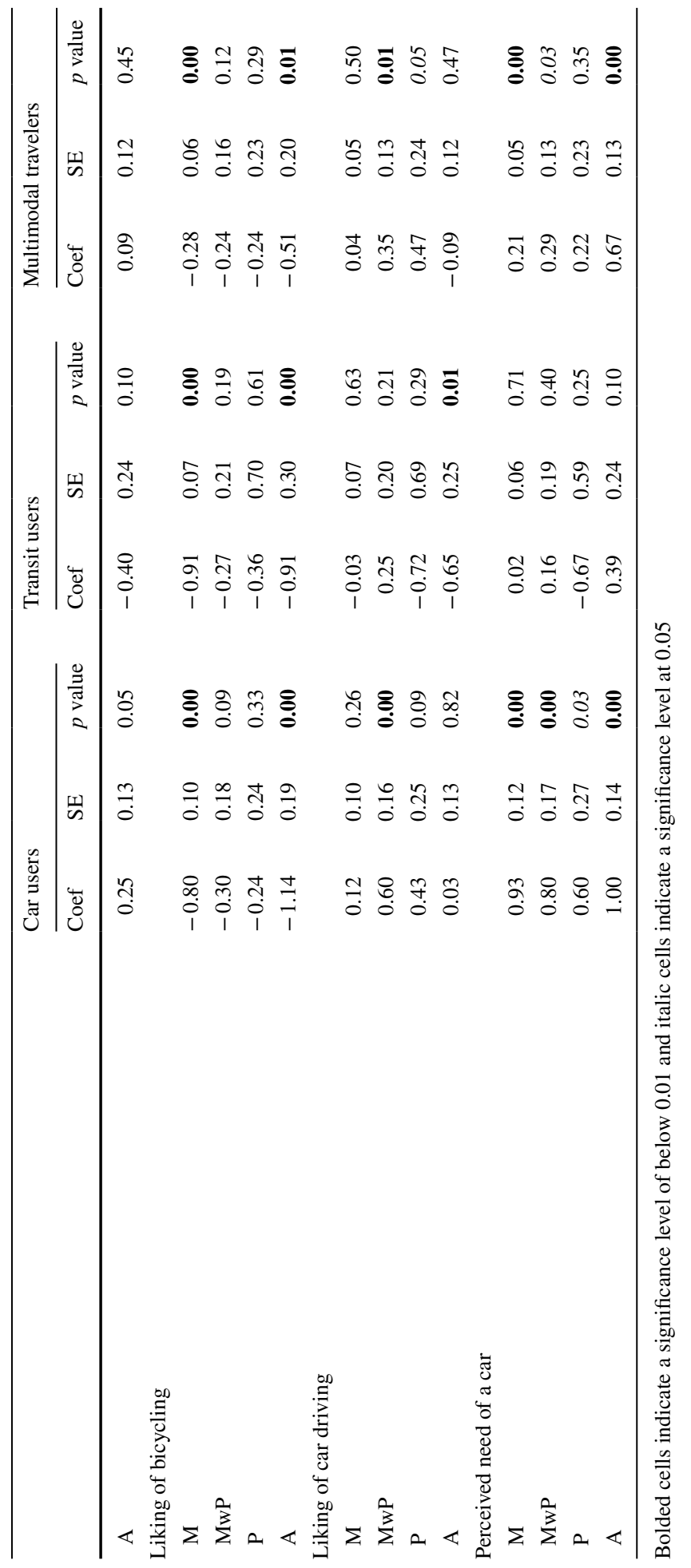




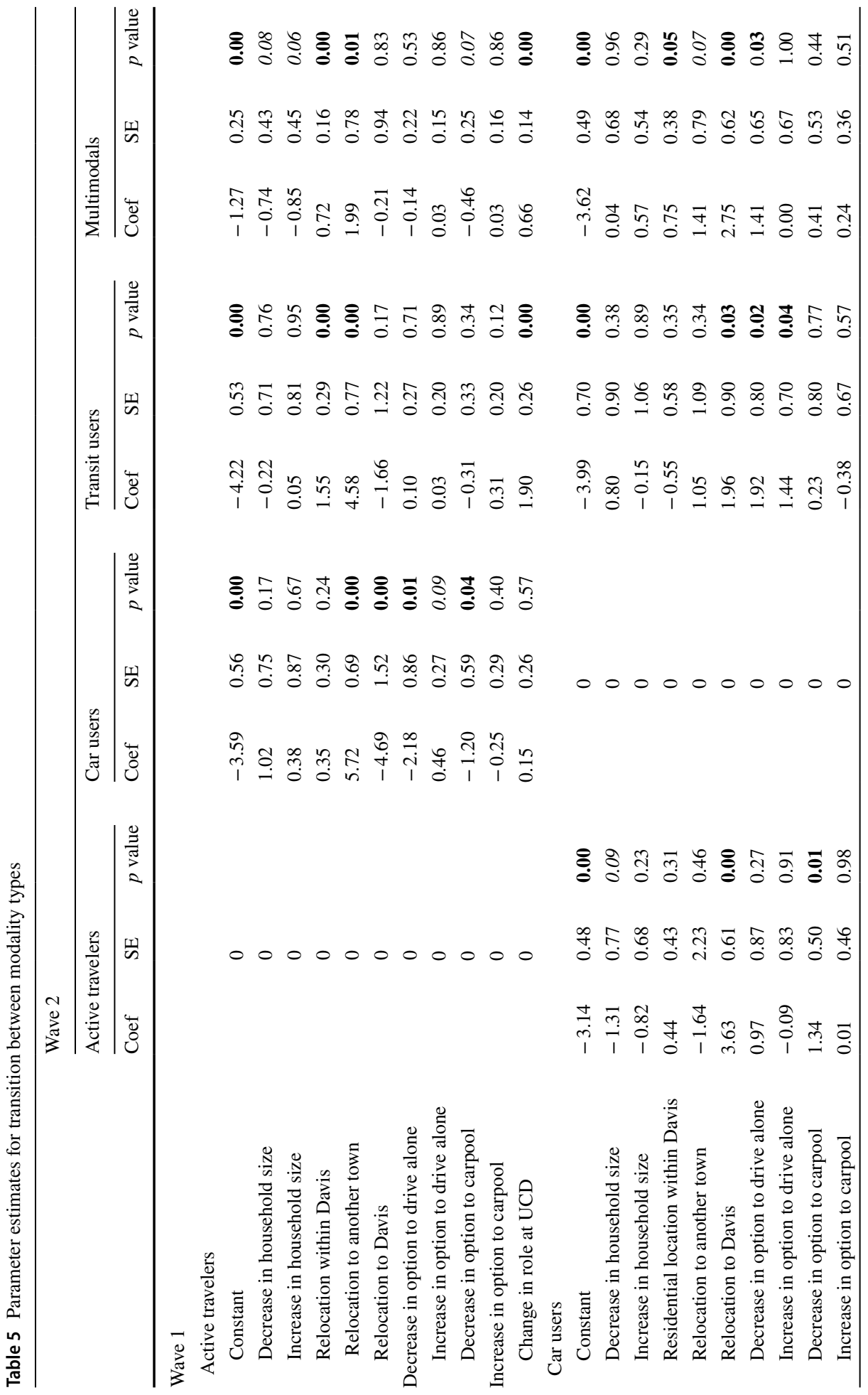




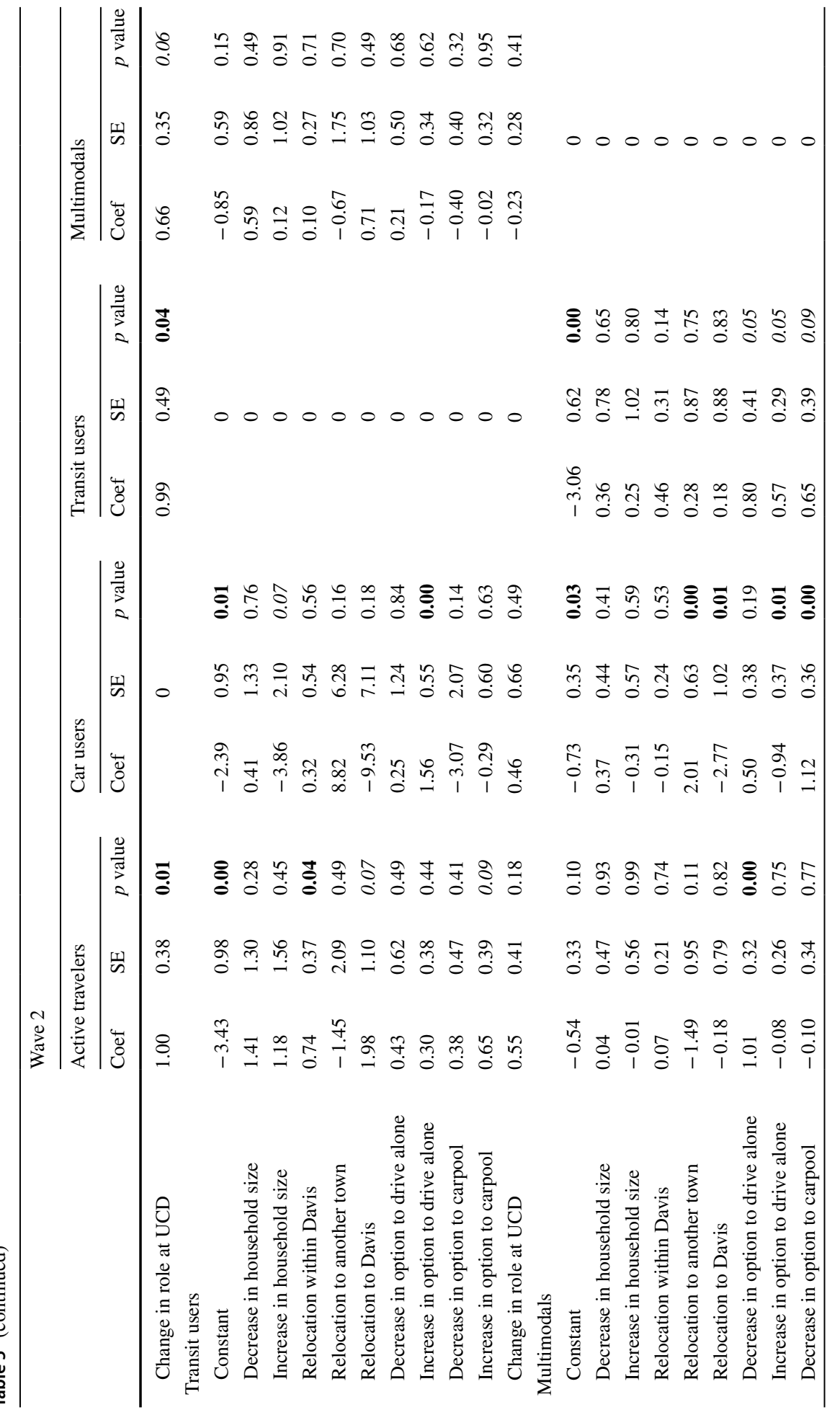




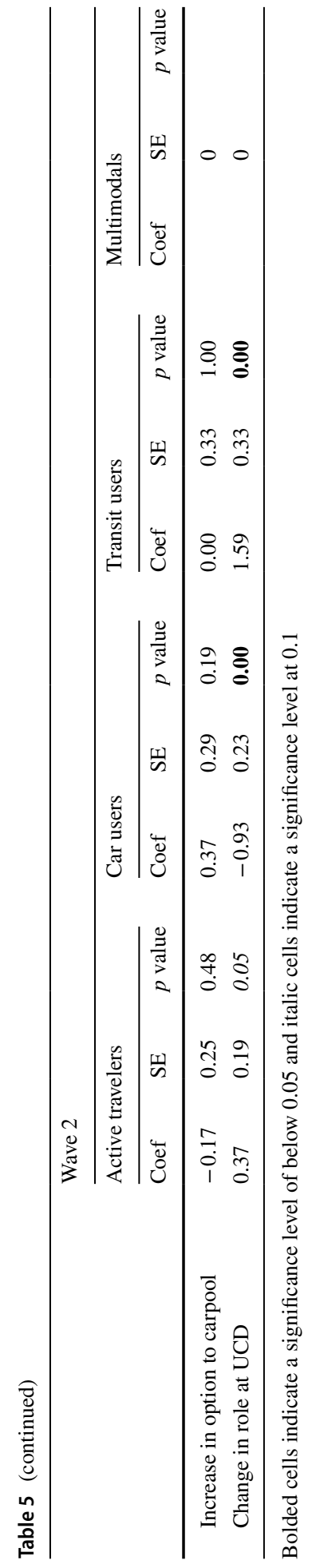




\section{References}

Bamberg, S.: Is a residential relocation a good opportunity to change people's travel behavior? Results from a theory-driven intervention study. Environ. Behav. 38, 820-840 (2006)

Beige, S., Axhausen, K.W.: The dynamics of commuting over the life course: Swiss experiences. Transp. Res. Part A Policy Pract. 104, 179-194 (2017)

Beige, S., Axhausen, K.W.: Long-term and mid-term mobility decisions during the life course. In: Paper Presented at the 87th Annual Meeting of the Transportation Research Board, Washington, DC, January 2008 (2008)

Bohnet, M., Gertz, C.: Model Event history of car and license availability: how accessibility shapes acquisition and disposal of cars. Transp. Res. Rec. 2156(1), 120-130 (2010)

Buehler, R., Hamre, A.: An examination of recent trends in multimodal travel behavior among American motorists. Int. J. Sustain. Transp. 10(4), 354-364 (2016)

Buehler, T., Handy, S.: Fifty years of bicycle policy in Davis, California. Transp. Res. Rec. 2074, 52-57 (2008)

Busch-Geertsema, A., Lanzendorf, M.: From university to work life-Jumping behind the wheel? Explaining mode change of students making the transition to professional life. Transp. Res. Part A Policy Pract. 106, 181-196 (2017)

Chatterjee, K., Goodwin, P., Schwanen, T., Clark, B., Jain, J., Melia, S., Middleton, J., Plyushteva, A., Ricci, M., Santos, G., Stokes, G.: Young people's travel: What's changed and why? Review and analysis. Project Report. Department for Transport, Bristol. http://eprints.uwe.ac.uk/34640 (2018). Accessed 22 February 2019

Chatterjee, K., Sherwin, H., Jain, J., Christensen, J., Marsh, S.: Conceptual model to explain turning points in travel behavior. Transp. Res. Rec. 2322, 82-90 (2012)

Chatterjee, K., Sherwin, H., Jain, J.: Triggers for changes in cycling: the role of life events and modifications to the external environment. J. Transp. Geogr. 30, 183-193 (2013)

Cheng, L., De Vos, J., Shi, K., Yang, M., Chen, X., Witlox, F.: Do residential location effects on travel behavior differ between the elderly and younger adults? Transp. Res. Part D Transp. Environ. 73, 367380 (2019)

Circella, G., Alemi, F., Tiedeman, K., Berliner, R.M., Lee, Y., Fulton, L., Mokhtarian, P.L., Handy, S.L.: NCST Research Report: What Affects Millennials' Mobility? PART II: The Impact of Residential Location, Individual Preferences and Lifestyle on Young Adults' Travel Behavior in California. Institute of Transportation Studies, University of California, Davis, Research Report UCD-ITS-RR-17-05 (2017). Accessed 05 August 2019

Clark, B., Chatterjee, K., Melia, S.: Changes to commute mode: the role of life events, spatial context and environmental attitude. Transp. Res. Part A Policy Pract. 89, 89-105 (2016)

Dargay, J.: The effect of income on car ownership: evidence of asymmetry. Transp. Res. Part A Policy Pract. 35, 807-821 (2001)

Dargay, J., Hanly, M.: Volatility of car ownership, commuting mode and time in the UK. Presented at the World Conference on Transport Research, Istanbul (2004)

De Haas, M.C., Scheepers, C.E., Harms, L.W.J., Kroesen, M.: Travel pattern transitions: applying latent transition analysis within the mobility biographies framework. Transp. Res. Part A Policy Pract. 107, 140-151 (2018)

Delbosc, A., Currie, G.: Causes of youth licensing decline: a synthesis of evidence. Transp. Rev. 33(3), 271-290 (2013)

Delbosc, A., Currie, G.: Changing demographics and young adult driver license decline in Melbourne, Australia (1994-2009). Transportation 41(3), 29-542 (2014a)

Delbosc, A., Currie, G.: Impact of attitudes and life stage on decline in rates of driver's license acquisition by young people in Melbourne, Australia. Transp. Res. Rec. 2452, 62-70 (2014b)

Delbosc, A., Nakanishi, H.: A life course perspective on the travel of Australian millennials. Transp. Res. Part A Policy Pract. 104, 319-336 (2017)

European Cyclists' Federation: Love to Ride 2015.: Bike2Work United Kingdom. http://www.bike2workproject.eu/en/Campaigns/United-Kingdom/Love-to-Ride-2015-CTC (2019). Accessed 26 February 2019

Fatmi, M.R., Habib, M.A.: Life-oriented approach of modeling commute mode loyalty and transition behavior. Transp. Res. Rec. 2565(1), 37-47 (2016)

Flamm, M., Kaufmann, V.: Operationalising the concept of motility: a qualitative study. Mobilities 1(2), 167-189 (2006)

Frey, R.M., Xu, R., Ilic, A.: Mobile app adoption in different life stages: an empirical analysis. Pervasive Mob. Comput. 40, 512-527 (2017) 
Gärling, T., Gillholm, R., Gärling, A.: Reintroducing attitude theory in travel behavior research: the validity of an interactive interview procedure to predict car use. Transportation 25, 129-146 (1998)

Gehrke, S.R., Singleton, P.A., Clifton, K.J.: Understanding stated neighborhood preferences: the roles of lifecycle stage, mobility style, and lifestyle aspirations. Travel Behav. Soc. 17, 62-71 (2019)

Gilly, M.C., Enis, B.M.: Recycling the family life cycle: a proposal for redefinition. Adv. Consum. Res. 9, 271-276 (1982)

Holz-Rau, C., Scheiner, J.: Mobilitätsbiografien und Mobilitätssozialisation: Neue Zugänge zu einem alten Thema. In: Scheiner, J., Holz-Rau, C. (eds.) Räumliche Mobilität und Lebenslauf. Studien zu Mobilitätsbiografien und Mobilitätssozialisation, pp. 3-22. Springer Fachmedien, Wiesbaden (2015)

Kroesen, M.: Modeling the behavioral determinants of travel behavior: an application of latent transition analysis. Transp. Res. Part A Policy Pract. 65, 56-67 (2014)

Kuhnimhof, T., Buehler, R., Wirtz, M., Kalinowska, D.: Travel trends among young adults in Germany: increasing multimodality and declining car use for men. J. Transp. Geogr. 24, 443-450 (2012)

Lanzendorf, M.: Mobility biographies. A new perspective for understanding travel behavior. Conference paper, 10th International Conference on Travel Behaviour Research, Lucerne 10-15, August 2003 (2003)

Lanzendorf, M.: Key events and their effect on mobility biographies: the case of childbirth. Int. J. Sustain. Transp. 4, 272-292 (2010)

League of American Bicyclists.: Bike Month Dates and Events. Washington, DC (2019). https://bikel eague.org/content/bike-month-dates-events-0. Accessed 05 August 2019

Lee, A.E., Underwood, S., Handy, S.: Crashes and other safety-related incidents in the formation of attitudes toward bicycling. Trans. Res. Part F Traffic Psychol. Behav. 28, 14-24 (2015)

Licaj, I., Haddak, M., Pochet, P., Chiron, M.: Individual and contextual socioeconomic disadvantages and car driving between 16 and 24 years of age: a multilevel study in the Rhône Département (France). J. Transp. Geogr. 22, 19-27 (2012)

McDonald, N.C.: Are millennials really the "Go-Nowhere" generation? J. Am. Plan. Assoc. 81(2), 90-103 (2015)

Molin, E., Mokhtarian, P., Kroesen, M.: Multimodal travel groups and attitudes: a latent class cluster analysis of Dutch travelers. Transp. Res. Part A Policy Pract. 83, 14-29 (2014)

Müggenburg, H., Busch-Geertsema, A., Lanzendorf, M.: Mobility biographies: a review of achievements and challenges of the mobility biographies approach and a framework for further research. J. Transp. Geogr. 46, 151-163 (2015)

Nordback, K.: Measuring traffic reduction from bicycle commuting. Trans. Res. Rec. 2468, 92-99 (2014)

Oakil, A.T.M., Ettema, D., Arentze, T., Timmermans, T.: Changing household car ownership level and life cycle events: an action in anticipation or an action on occurrence. Transportation 41, 889-904 (2014)

Oakil, A.T.M., Ettema, D., Arentze, T., Timmermans, H.: Bicycle commuting in the Netherlands: an analysis of modal shift and its dependence on life cycle and mobility events. Int. J. Sustain. Transp. 10(4), 376-384 (2016)

Oostendorp, R.: Wohnstandortentscheidungen von Doppelverdienerhaushalten. Zum Zusammenwirken von Wohnen und Arbeiten in der polyzentrischen Stadtregion Köln/Bonn. Doctoral Thesis, Rheinischen Friedrich-Wilhelms-Universität Bonn (2014)

Rabe, B., Taylor, M.: Residential mobility, quality of neighbourhood and life course events. R. Stat. Soc. Ser. A 173(3), 531-555 (2010)

Raimond, T., Milthorpe, F.: Why are young people driving less? Trends in licence-holding and travel behavior. Australian Transport Research Forum 2010 Proceedings, 29-Septemper-1.October 2010, Canberra, Australia (2010)

Scheiner, J.: Gendered key events in the life course: effects on changes in travel mode choice over time. J. Transp. Geogr. 37, 47-60 (2014)

Scheiner, J., Holz-Rau, C.: A comprehensive study of life course, cohort, and period effects on changes in travel mode use. Transp. Res. Part A Policy Pract. 47, 167-181 (2013)

Scheiner, J., Holz-Rau, C.: Räumliche Mobilität und Lebenslauf. Studien zu Mobilitätsbiografien und Mobilitätssozialisation. Springer Fachmedien, Wiesbaden (2015)

Scheiner, J., Chatterjee, K., Heinen, E.: Key events and multimodality: a life course approach. Transp. Res. Part A Policy Pract. 91, 148-165 (2016) 
Sharmeen, F., Arentze, T., Timmermans, H.: An analysis of the dynamics of activity and travel needs in response to social network evolution and life-cycle events: a structural equation model. Transp. Res. Part A Policy Pract. 59, 159-171 (2014)

Smart, M.J., Klein, J.N.: Remembrance of Cars and buses past: how prior life experiences influence travel. Transp. Res. Rec. 38(2), 139-151 (2017)

Sun, Y., Waygood, E.O.D., Fukui, K., Kitamura, R.: Built environment or household life-cycle stages: which explains sustainable travel more? Case of Kyoto-Osaka-Kobe, Japan, built area. Transp. Res. Rec. 2135, 123-129 (2009)

Thierstein, A., Wulfhorst, G., Bentlage, M., Klug, S., Gilliard, L., Ji, C., Kinigadner, J., Steiner, H., Sterzer, L., Wenner, F., Zhao, J.: WAM Wohnen Arbeiten Mobilität. Veränderungsdynamiken und Entwicklungsoptionen für die Metropolregion München, Lehrstuhl für Raumentwicklung und Fachgebiet für Siedlungsstruktur und Verkehrsplanung der Technischen Universität München, http://mediatum. ub.tum.de/node?id=1292926 (2016). Accessed 9 March 2017

Thigpen, C.: Do bicycling experiences and exposure influence bicycling skills and attitudes? Evidence from a bicycle-friendly university. Transp. Res. Part A Policy Pract. 123, 68-79 (2019)

Thigpen, C., Handy, S.: Driver's licensing delay: a retrospective case study of the impact of attitudes, parental and social influences, and intergenerational differences. Transp. Res. Part A Policy Pract. 111, 24-40 (2018)

Van Acker, V.: Lifestyles and life choices. In: Zhang, J. (ed.) Life-orientated Behavioral Research for Urban Policy, pp. 76-96. Springer, Tokyo (2017)

Van der Waerden, P., Timmermans, H., Borgers, A.: The influence of key events and critical incidents on transport mode choice switching behaviour: a descriptive analysis. Presented at the 10th International Conference on Travel Behaviour Research, Lucerne (2003)

Verhoeven, M., Arentze, T., Timmermans, H.J.P., van der Waerden, P.: Modeling the impact of key events on long-term transport mode choice. decisions decision network approach using event history data. Trans. Res. Rec. 1926, 106-114 (2005)

Vermunt, J.K., Magidson, J.: LG-SyntaxTM User's Guide: Manual for Latent GOLD 5.0 Syntax Module1. Statistical Innovations Inc., Belmont (2015)

Vermunt, J.K., Magidson, J.: Technical Guide for Latent GOLD 5.1 (2016) Basic, Advanced, and Syntax. Statistical Innovations Inc., Belmont (2016)

Vermunt, J.K., Magidson, J.: LatentGOLD version 5.1. Statistical Innovations Inc., Belmont (2017)

Vij, A., Carrel, A., Walker, J.L.: Incorporating the influence of latent modal preferences on travel mode choice behavior. Transp. Res. Part A Policy Pract. 54, 164-178 (2013)

Wang, B., Rasouli, S., Timmermans, H., Shao, S.: Relationships between consecutive long-term and midterm mobility decisions over the life course: a Bayesian network approach. Trans. Res. Rec. 2672(47), $1-12(2018)$

Wei, A.: Results of the 2017-18 Campus Travel Survey. Institute of Transportation Studies, University of California, Davis, Research Report UCD-ITS-RR-18-15 (2018)

Zhang, J.: Life-Orientated Behavioral Research for Urban Policy. Springer, Tokyo (2017)

Zhang, J., Van Acker, V.: Life-oriented travel behavior research: an overview. Transp. Res. Part A Policy Pract. 104, 167-178 (2017)

Zhang, J., Kuwano, M., Chikaraishi, M., Seya, H.: The car-dependent life. In: Zhang, J. (ed.) Life-Orientated Behavioral Research for Urban Policy, pp. 97-122. Springer, Tokyo (2017)

Publisher's Note Springer Nature remains neutral with regard to jurisdictional claims in published maps and institutional affiliations.

Julia Janke is a research assistant and $\mathrm{PhD}$ candidate at the Department of Spatial Planning at TU Wien, Austria. In her $\mathrm{PhD}$ thesis, she investigates the relationship between travel attitudes, travel behavior and life events. Her past research concerns travel behavior change over time, intra-household interactions and is embedded in the mobility biography literature. Previously, she investigated the implications of travel on energy consumption in California, US and India. 
Calvin G. Thigpen is the Policy Research Manager at Lime. Calvin received his $\mathrm{PhD}$ in Transportation Technology and Policy at the University of California at Davis and worked as a post-doctoral researcher in the School of Geographic Sciences and Urban Planning at Arizona State University. His research interests include bicyclist behavior and safety; the development of travel skills and attitudes; and parking behavior.

Susan Handy is a Professor in the Department of Environmental Science and Policy and the Director of the National Center for Sustainable Transportation at the University of California, Davis. She is internationally known for her research on the relationships between transportation and land use, particularly the impact of neighborhood design on travel behavior. Her current work focuses on bicycling as a mode of transportation and on strategies for reducing automobile dependence. 